\title{
Long-term dynamic bearing capacity of shallow foundations on a contractive cohesive soil
}

\author{
Daniel R. Panique Lazcano ${ }^{1}$ (D) $\cdot$ Rubén Galindo Aires ${ }^{1} \cdot$ Hernán Patiño Nieto ${ }^{2}$
}

Received: 29 December 2020 / Accepted: 16 July 2021 / Published online: 5 August 2021

(C) The Author(s) 2021

\begin{abstract}
The calculation of the long-term dynamic bearing capacity arises from the need to consider the generation of maximum pore-water pressure developed from a cyclic load. Under suitable conditions, a long-term equilibrium situation would be reached, when pore-water pressures stabilized. However, excess pore-water pressure generation can lead to cyclic softening. Consequently, it is necessary to define both the cohesion and the internal friction angle to calculate the dynamic bearing capacity of a foundation in the long term, being necessary to incorporate the influence of the self-weight of soil and therefore the width of the foundation. The present work is based on an analysis of the results of cyclic simple shear tests on soil samples from the port of El Prat in Barcelona. From these experimental data, a pore-water pressure generation formulation was obtained that was implemented in FLAC2D finite difference software. A methodology was developed for the calculation of the maximum cyclic load that a footing can resist before the occurrence of the cyclic softening. The type of soil studied is a contractive cohesive soil, which generates positive pore-water pressures. As a numerical result, design charts have been developed for long-term dynamic bearing capacity calculation and the charts were validated with the application of a real case study.
\end{abstract}

Keywords Cyclic load · Dynamic bearing capacity · Finite difference method · Pore-water pressure generation · Self-weight

\section{Introduction}

The bearing capacity of shallow foundations has always been a topic that has generated a lot of attention from researchers. From the beginning, the classical methods for the analysis of the static bearing capacity were developed, to later and up to the present time, advance in the study of the bearing capacity in the presence of dynamic load. The first works on dynamic bearing capacity were associated with liquefaction phenomena in granular soils, giving less attention to cohesive soils. The first studies of bearing capacity under dynamic load were approached by Meyerhof $[39,40]$ and Shinohara [55] who reduced the seismic

Daniel R. Panique Lazcano

dr.panique@alumnos.upm.es

1 ETSICCP, Universidad Politécnica de Madrid, c/Profesor Aranguren s/n, Madrid 28040, Spain

2 ICG, Instituto Colombiano de Investigaciones Geotécnicas, Bogotá, Colombia case to an equivalent static case under inclined and eccentric loads. Subsequently, Sarma and Iossifelis [51] addressed the problem assuming a certain failure mechanism where the active wedge, the passive wedge, and a logarithmic spiral shear zone were defined based on certain equivalent static conditions. Budhu and Al-Karni [11] evaluated the seismic bearing capacity considering the horizontal and vertical accelerations, the applied loads, and the effects of the inertial forces of the soil below and above the footing.

The evaluation of the bearing capacity of foundations under dynamic loading using pseudo-static solutions has become widespread $[6,29,30]$. These pseudo-static solutions have grown in recent years and have made it possible to generate design criteria and reduction factors to solve the problem of dynamic bearing capacity $\left(\mathrm{Ph}_{\mathrm{d}}\right)$. Others have suggested studying the $\left(\mathrm{Ph}_{\mathrm{d}}\right)$ through sophisticated dynamic constitutive models or researchers that require a greater effort to identify parameters and numerical management $[5,24,41]$. However, many investigations do not 
consider the generation of pore-water pressure, although this is one of the most important factors. The main characteristic of the generation of pore-water pressure in cohesive soils is that it can carry out a sudden breakdown of the soil without the need for the effective stress to be canceled as in the case of granular soils. This phenomenon is called cyclic softening and is described as the development of significant deformations or the loss of resistance in clays $[9,15,27,48]$.

One of the first to investigate the generation of porewater pressure were Booker et al. [8], who developed a method of analysis of equations governing the generation and dissipation of pore-water pressure based on the finite element method. It was a few years later when Ohara and Matsuda [42] studied saturated clays under cyclic load and determined that they depend on various factors, such as the amplitude of the cyclic shear strain, number of cycles, and the overconsolidation ratio. But it was not until the 1990s when a series of earthquakes Northridge (1994), Kocaeli (1999) and Chi-Chi (1999) that caused considerable damage to important structures that the study of pore-water pressure generation was intensified in cohesive soils. As a result of these events, various investigations arise; Sitharam and Govindaraju [56] indicated that new studies have made it possible to incorporate pore-water pressure accumulation rates in nonlinear response analyses of soils to seismic load. Saglam and Bakir [50] focus on the study of pore-water pressure under repeated load and the relationship between cyclic strain and excess pore-water pressure in soils with low plasticity.

The generation of pore-water pressure is directly related to the number of cycles; therefore, under suitable conditions, a long-term equilibrium situation would be reached where pore-water pressures stabilize. Thus, the need arises to calculate the long-term dynamic bearing capacity, so that the maximum pore-water pressure generation developed can be considered. Consequently, it is necessary to define both the cohesion and the internal friction angle to calculate the bearing capacity of a foundation in the long term, being necessary to incorporate the influence of the weight of the soil and therefore the width of the foundation. In static calculations, the weight of the soil is of decisive importance if the situation is analyzed in the long term and added to the analytical solution as an empirical term. Similarly, for the study of the dynamic bearing capacity of a foundation in the long term, it is necessary to incorporate the own weight of the soil and complete some of the solutions provided in the bibliography that do not consider this factor [45].

In the present work, the dynamic bearing capacity is studied in long-term shallow foundations in cohesive soils. It starts from an analysis of the results of cyclic simple shear tests on soil samples from the port of El Prat in
Barcelona [46]. It should be noted that there is no test that represents all possible stress and strain path, nor the rotation of the axes of the main stress; therefore, the most suitable test depends on the problem. In the particular case of this research, the influence of the combination of monotonic and cyclic shear stresses on the development of pore-water pressure was investigated under conditions idealized by the cyclic simple shear test. This test has the advantages of keeping the cross section of the samples constant and guarantees uniform axial deformations during the consolidation process, and, fundamentally, it is the test that best reproduces the field conditions because the consolidation occurs in the $k_{o}$-state. From these experimental data, a pore-water pressure generation formulation was obtained that was implemented in a FLAC2D finite difference software [28]. A methodology was developed for the calculation of the maximum cyclic load that a footing can resist was obtained before cyclic softening occurs. The type of soil studied is a contractive cohesive soil which generates positive pore-water pressures and allows the calculation of long-term dynamic bearing capacity. From this, design charts have been developed for long-term dynamic calculation based on the width of the foundation. Finally, the validation of the methodology was carried out with the application to a real case reported in various publications.

\section{Background}

\subsection{Bearing capacity}

The static bearing capacity of shallow foundations has been extensively studied over time. However, the dynamic bearing capacity in shallow foundations did not receive the same attention despite being important for the design of offshore structures, which are close to the coast or on land [4, 49]. Hu et al. [24] showed the complex behavior of a normally consolidated soft clay under seismic load and different parameters that influence the results of multidirectional cyclic simple shear tests. For the analysis of the bearing capacity, Cascone and Casablanca [13] mention different methods, analytical solutions such as limit equilibrium, limit analysis (upper and lower contour), and the method of characteristic lines or numerical solutions as the finite element method and the finite difference method.

One of the first analytical solutions to calculate the dynamic bearing capacity was the limit equilibrium. Sarma and Iossifelis [51] used the technique by inclined slices and assuming failure mechanisms similar to static conditions. Budhu and Al-Karni [11] considered the vertical acceleration, the inertial force on the soil mass, and the applied load, which resulted in a shallower failure surface 
concerning the static case as shown in Fig. 1. For their part, Choudhury and Subba Rao [14] assumed a composite failure surface that involves a flat surface and a logarithmic spiral, to calculate the seismic bearing capacity. Jadar and Ghosh [30] evaluated the seismic bearing capacity of strip footing using horizontal slices considering a nonlinear failure surface. Izadi et al. [29] evaluated using a pseudostatic approach, the effect of the variation in the shear strength without drainage with depth on the seismic bearing capacity by applying the limit equilibrium method associated with the failure mechanism of Coulomb. Conti [16] worked on the seismic bearing capacity of strip footings under a pseudo-static approach using the limit analysis method in cohesive frictional and purely cohesive soils. However, parameters such as pore-water pressure or shear strength of the soil due to the seismic effect are not considered. Cascone and Casablanca, Choudhury and Rao, Conti, Kumar and Rao [13, 14, 16, 32] applied the analysis of the seismic bearing capacity with the use of the characteristic lines method to evaluate the effect of the horizontal seismic forces in foundations.

On the other hand, within the numerical solutions, Pane et al. [43] worked under the pseudo-static approach with the finite differences method to evaluate the seismic effects on the bearing capacity of strip footing incorporating the inertia of the structure and inertia of the soil. Nazem et al. [41] worked with the Arbitrary Lagrangian-Eulerian method (ALE) that addresses non-linearity due to material behavior, large strains, changing boundary conditions, and time dependence, for determination of the dynamic bearing capacity of footing in soft soils.

Inside the pseudo-static approaches, the action of the earthquake in a foundation is divided into two components. The first component of structural inertia is caused by the inertial forces that act on the superstructure and are transmitted to the foundation by shear; the second corresponds to a component of inertia of the soil called "kinematic effect" that is due to the inertial forces that act in the soil mass [43]. In the literature, both components are addressed separately or according to combined solutions. Other studies estimate the dynamic bearing capacity for different local failure mechanisms: rocking, suppression, or sliding wedge of a foundation [3, 21, 23]. Barrios et al. [5] analyzed the dynamic response of footings using an experimental approach from results on a vibrating table. A complete seismic analysis involves making a dynamic and time-history analysis that is complex to apply in practice. Therefore, most seismic designs are based on equivalent pseudo-static approaches for which a constant horizontal seismic coefficient is assigned.

\subsection{Generation of pore-water pressure}

The generation of pore-water pressure is an essential aspect to carry out the study of dynamic bearing capacity since it substantially conditions the response of a cohesive medium. The generation of pore-water pressure in cohesive soils has been studied to a lesser extent than in granular soils. An increase in the generation of pore-water pressure can lead to the phenomenon of cyclic softening. This phenomenon is described as the development of significant strains or the loss of resistance in clays with the reduction in stiffness of the soil due to a cyclic load [9, 15, 27, 48]. From various investigations, two methods of analyzing the response of excess pore-water pressure arisen: the first, Lee and Albaisa [33] suggested analyzing the pore-water pressure with the relationship between the number of cycles and the cycles necessary to cause liquefaction, and the second, Dobry et al. [17] suggest analyzing pore-water pressure in terms of strains.

Formulations and models were developed over time to describe the behavior of pore-water pressure generation.

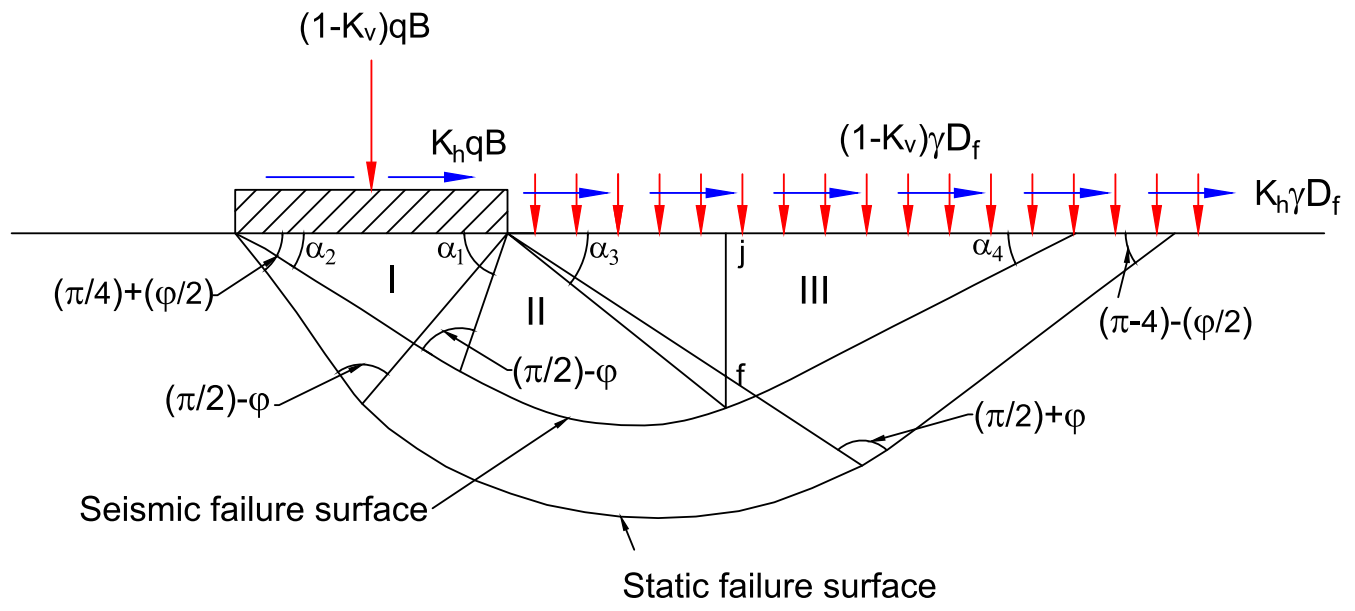

Fig. 1 Comparison of static and seismic failure surface [11] 
One of them is Seed et al. [53] based on energetic methods. Other authors such as Martin et al., Byrne [12, 35] or Matasovíc and Vucetic [38] developed a generalized degradation pore-water pressure generation model. This model expresses cyclic resistance with pore-water pressure cyclic and stiffness degradation rate, under the concept of the cyclic volumetric threshold shear stress. Hyde and Ward [25] proposed a potential model for pore-water pressure generation in silty clay fitted to cyclic triaxial tests. Hyodo et al. [26] proposed a semi-empirical model to evaluate the development of pore-water pressure and residual shear strain during cyclic loading. Yasuhara [58] proposed an empirical method that depends on the plasticity index to predict the changes due to the degradation of the resistance due to the increase in pore-water pressure in cohesive soils. Green et al., Polito et al. [22, 48] developed the GMP model, which relates the generation of residual pore-water pressure with the energy dissipated per unit volume of the soil. In turn, they analyzed the applicability of the GMP model to predict pore-water pressure generation in non-plastic silty soil during cyclic loading. Ajmera et al. [1] investigated the cyclic behavior of clays and saw as a result that soils become increasingly resistant to cyclic load as the plasticity index increases. Saglam and Bakir [50] proposed a model for the generation of pore-water pressure under cyclic loading based on the pore-water pressure ratio normalized by the confining stress and the number of cycles. Ren et al. [49] proposed a hyperbolic model to predict the development of undrained pore-water pressure. Shi et al. [54] proposed a constitutive model to simulate the degradation of the cyclical resistance of natural clays as a result of the loss of structure and accumulation of pore-water pressure. Galindo et al. [18-20] propose by evaluating the degradative damage produced, resolve the evolution of the cycles, and generate pore-water pressure under load cyclic, using a mathematical hysteresis model. Karakan et al. [31] evaluated the cyclic behavior of non-plastic silts with pore pressure ratios less than $50 \%$.

\section{Laboratory tests}

\subsection{Description of experimental data}

The present work used tests of unaltered samples from two borings, SA-1 and SA-2, located between 30 and $52 \mathrm{~m}$ deep concerning sea level from the port of the Prat in Barcelona. The soil was classified as silty clays and clayey silts of low to medium plasticity, from the samples belonging to a soil deposit of alluvial origin corresponding to the recent Quaternary (Holocene). From previous studies, Alonso and Gens [2] describe the area dividing it into four strata: The first stratum has a thickness of $50 \mathrm{~m}$ formed by silts and clays with a certain content of organic matter, existing intercalations of sand and sandy silt in the upper part. The second layer is $7 \mathrm{~m}$ thick and is made up of gravel and sand with some presence of silt. The third layer is $14 \mathrm{~m}$ thick, made up of clays like layer 1 but with a higher density. The fourth stratum has a thickness greater than 40 $\mathrm{m}$ and is gravel and sand with interlayers of clay. Moreover, Patiño et al. and Martinez et al. [37, 47] have described the behavior of the soil as typically plastic, with evidence of a contractive behavior due to the positive porewater pressure; therefore, it corresponds to a soil that is normally consolidated or with a low degree of consolidation.

The geotechnical characterization tests and monotonic and cyclic simple shear tests were carried out at the Escuela de Caminos, Canales y Puertos of the Universidad Politécnica de Madrid. The geotechnical characterization indicated that the average natural moisture is $29.24 \%$ within a range of 24 to 37 . The apparent density had an average value of $1970 \mathrm{~kg} / \mathrm{m}^{3}$ from a range of 1850 to 2080 $\mathrm{kg} / \mathrm{m}^{3}$. The fines content has an average value of $98.66 \%$ for a range of 87.26 to $99.99 \%$. The percentage of particles with a diameter of fewer than 2 microns has an average value of $30.21 \%$ for a range of 14 to 41 . The plasticity index has an average value of $17.67 \%$ within a range of 12.3 to 19.90 . Meanwhile, the monotonic and cyclic simple shear tests were carried out for various combinations of tangential stresses as indicated in Fig. 2.

\subsection{Monotonic and cyclic simple shear tests}

The present work studies the behavior of 78 cyclic simple shear tests and 16 monotonic simple shear tests of a cohesive soil applied to the stress combinations indicated in Fig. 2. On the vertical axis, the cyclic shear stress $\left(\Delta \tau_{\mathrm{c}}\right)$

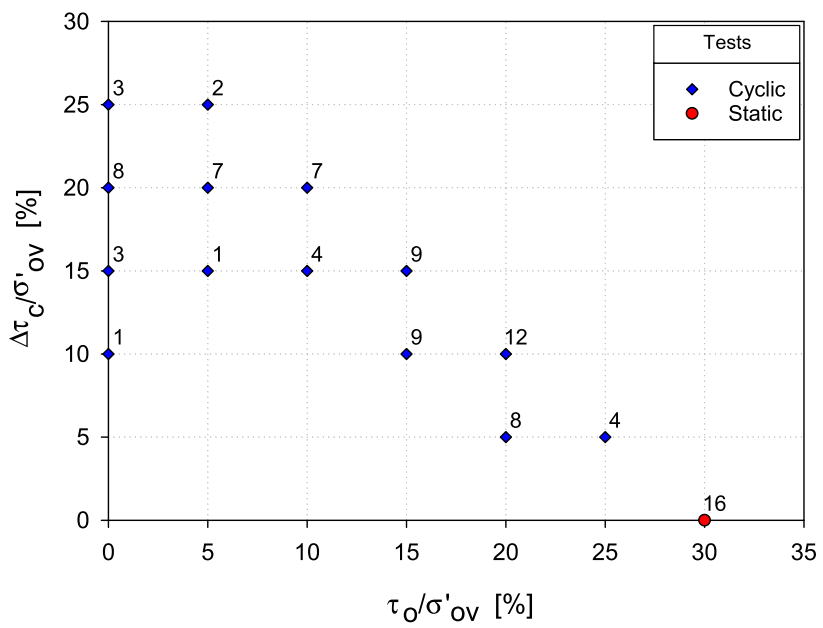

Fig. 2 Combination of stresses used to static and cyclic simple shear tests 
normalized concerning to the effective vertical consolidation stress $\left(\sigma_{\mathrm{ov}}^{\prime}\right)$, and on the horizontal axis, the static shear stress $\left(\tau_{o}\right)$ normalized concerning to the effective vertical consolidation stress $\left(\sigma_{\mathrm{ov}}^{\prime}\right)$. The 16 monotonic simple shear tests can be observed for a null normalized cyclic shear stress and normalized static shear stress of $30 \%$. The 78 cyclic simple shear tests were performed for sinusoidal wave with an amplitude equal to the cyclic shear stress $\left(\tau_{\mathrm{c}}\right)$ and a period of $10 \mathrm{~s}$.

The tests were carried out on saturated samples under the criteria of Bjerrum and Landva [7], which indicates that a simple shear test at constant volume is equivalent to an undrained test. The following conditions were also established:

- Undrained conditions and evaluation of pore-water pressure generation.

- Finalization of the test if it reaches permanent shear strain $\left(\gamma_{p}\right)$ of $15 \%$ or for cyclic strains $\left(\gamma_{c}\right)$ of $15 \%$, number of cycles $(N)$ of 1300 or the generation of porewater pressure of $95 \%$ of the consolidation stress.

- Undisturbed samples.

\section{Analysis of experimental results}

\subsection{Laboratory results}

The analysis of the behavior of a contractive cohesive soil under cyclic load was studied from results of the cyclic simple shear tests and considered two relationships. The first relationship is the increase in pore-water pressure with the number of cycles (Fig. 3). The second relationship is about shear stress with the shear strain (Fig. 4). Table 1 presents the combination of static and cyclic shear stresses, showing a summary of the results of some of the tests analyzed, and explains Figs. 3 and 4. It is observed that small values of the initial static stress ratio and high values of the cyclic shear stress ratio correspond to smaller values of excess pore-water pressures.

In Fig. 3, it can be observed for each figure from (a) to part (f) that with conditions being equal (equal confinement, void ratio, and initial static stress ratio) more pore pressure generation is obtained for higher values of cyclic shear stress. On the other hand, between each one of the figures, a higher initial static stress results in a lower generation of pore pressure because lower cyclic shear stress will be subjected. Greater cyclic shear stress concerning the total (lower static stress) requires fewer cycles to reach the ultimate state of the soil since greater damage is always caused by greater amplitudes of cyclic load. However, the accumulation of permanent strain is fundamentally due to the non-symmetrical load that is induced by the proportion of static load for the total, so that each new cycle generates less damage to the sample because it acts less cyclic load but accumulates more permanent strain. Thus, comparing, for example, Figs. 3c and $4 \mathrm{c}$ with Figs. $3 \mathrm{e}$ and $4 \mathrm{e}$, it is observed that the sample reached its ultimate state with 15 and 500 cycles, respectively. In the first case, it is due to reaching large cyclic shear stresses in each new cycle which, due to their largeamplitude, induce large pore-water pressures, while in the second case it is due to a strain accumulated throughout the cycles that after 500 reaches high permanent strain values but each cycle provides little cyclic strain and little porewater pressure. A more detailed analysis of pore-water pressure generation will be developed in the next section 4.2.

Something very similar happens if it analyzes the number of cycles; that is, two behaviors occur for the same initial shear stress values. For initial shear stress values of 0.5 and $10 \%$ (Fig. $3 a-c$ ), the number of cycles is very random being from a range of 15-500 cycles when the failure occurs. However, for values of initial shear stresses of 15 and $20 \%$ (Fig. 3d, e) the number of cycles becomes constant with a value of 1300 cycles when the soil failure occurs.

On the other hand, if it analyzes the stress-strain shear relationship for all the data shown in Table 1, it is observed that the total shear strain has a cyclic component $\left(\gamma_{c}\right)$ and a permanent component $\left(\gamma_{p}\right)$. Figure 4 shows only 6 stressstrain shear graphs that are representative for observing the variation that each one of them has as a function of the number of cycles $(N)$.

For initial shear stress values of 0,5 , and $10 \%$, the higher the cyclic shear stress, the lower is the permanent strain $\left(\gamma_{p}\right)$ that accumulates with the cycles, but the greater the cyclic strain $\left(\gamma_{c}\right)$. On the other hand, for initial shear stress values of 15 and $20 \%$, there is a trend toward greater cyclic shear stress, greater permanent strain, and greater cyclic strain.

\subsection{Pore-water pressure generation}

An analysis of tests was carried out based on measured parameters such as the voids ratio, initial shear stress, and cyclic shear stress. The behavior of the void ratio was analyzed with the normalized cyclic shear stress, and a linear behavior of the data with an average value of 0.82 was obtained as the best fit. On the other hand, the behavior analysis of the pore-water pressure generation was performed with the normalized initial and cyclical shear stress. The pore-water pressure decreases as the initial shear stress increases while it increases with the normalized cyclic 

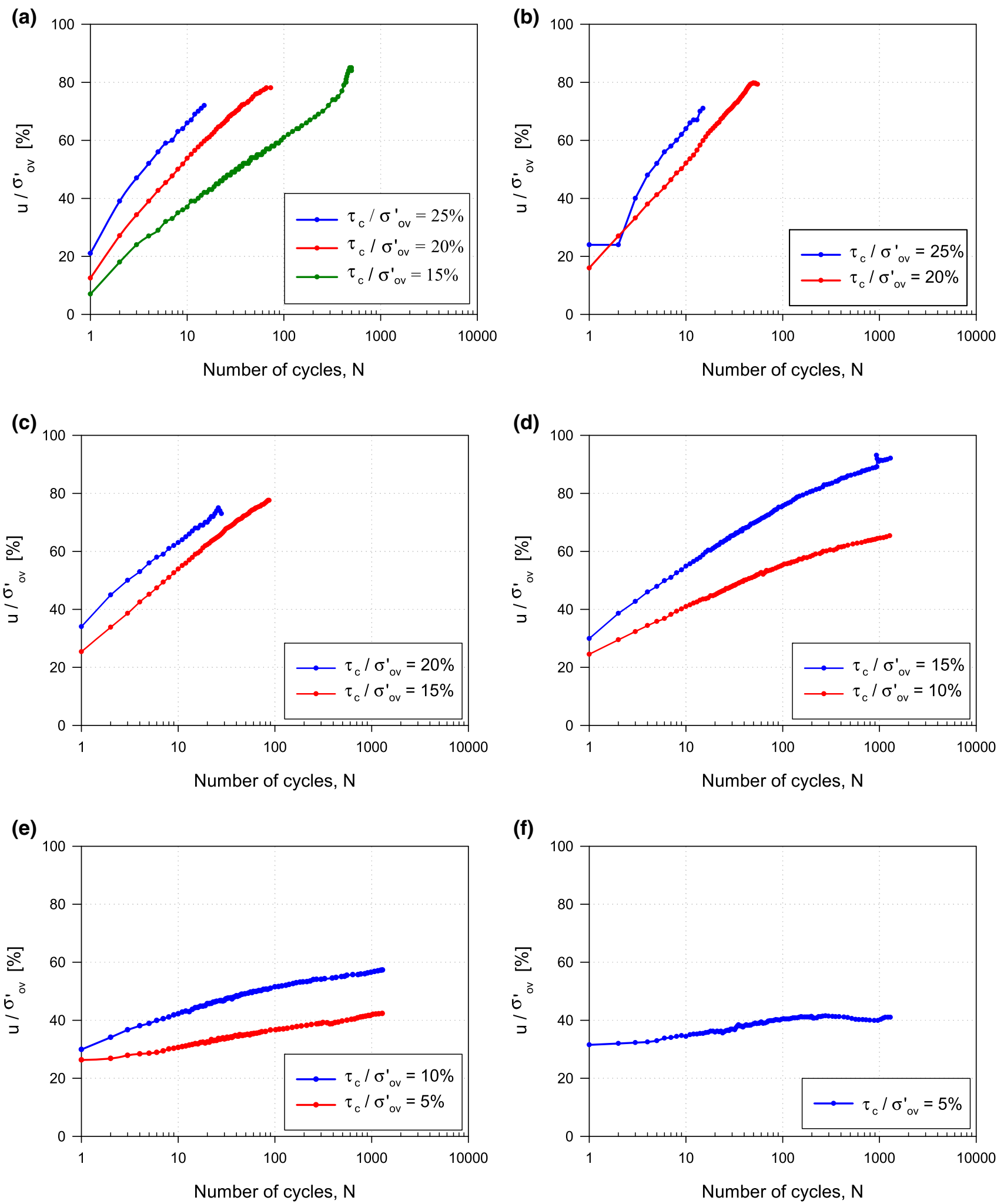

Fig. 3 Relationship of the increase in pore-water pressure generation with the number of cycles: a $\tau_{o} / \sigma_{\mathrm{ov}}^{\prime}=0 ; \mathbf{b} \tau_{o} / \sigma_{\mathrm{ov}}^{\prime}=5 \%$; $\tau_{o} / \sigma_{\mathrm{ov}}^{\prime}=10 \%$; d $\tau_{o} / \sigma_{\mathrm{ov}}^{\prime}=15 \%$; $\tau_{o} / \sigma_{\mathrm{ov}}^{\prime}=20 \% ; \mathbf{f} \tau_{o} / \sigma_{\mathrm{ov}}^{\prime}=25 \%$ 
(a)

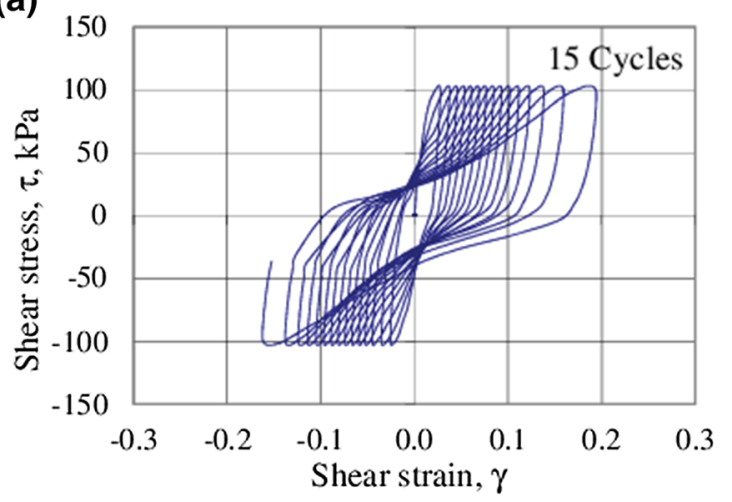

(c)

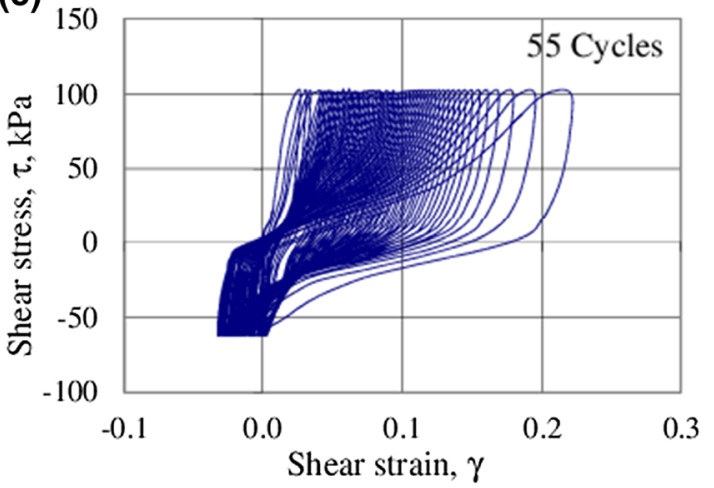

(e)

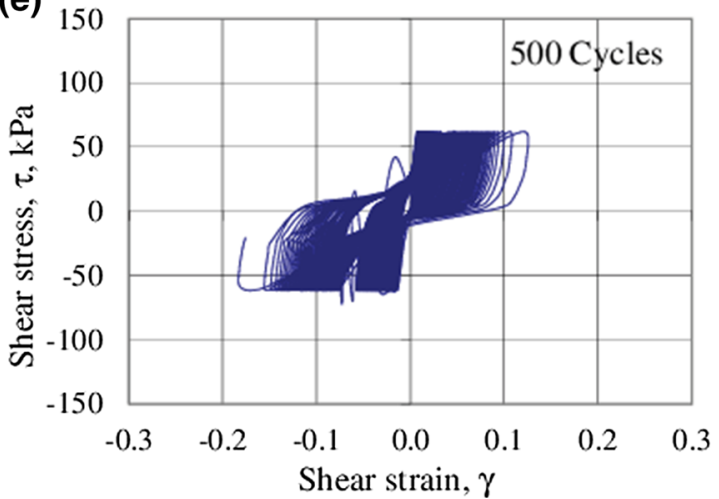

(b)

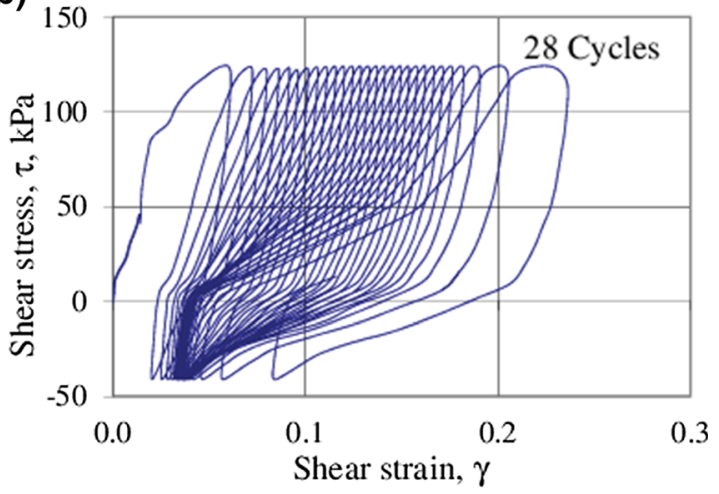

(d)

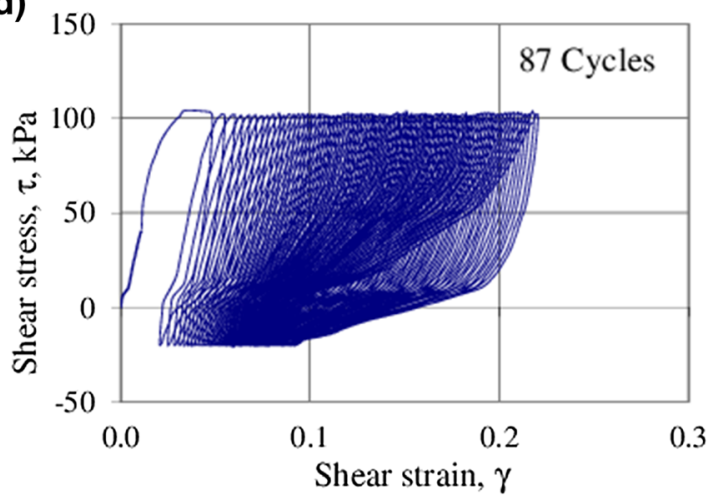

(f)

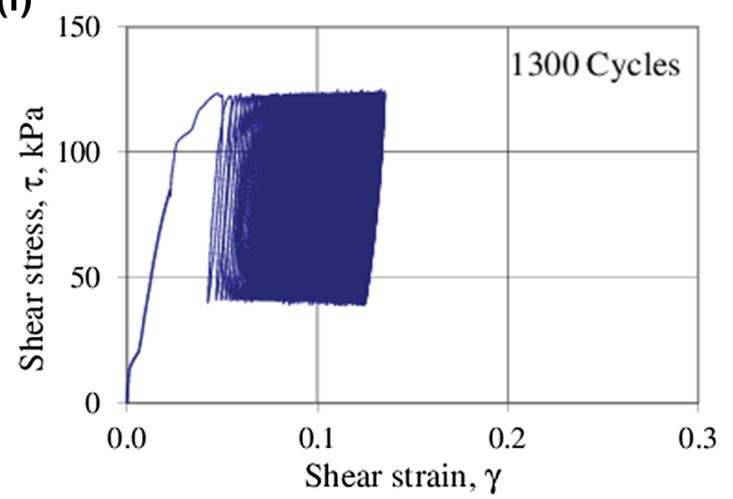

Fig. 4 Relationship of shear stress with shear strain. a $\tau_{o} / \sigma_{\mathrm{ov}}^{\prime}=0$ and $\tau_{\mathrm{c}} / \sigma_{\mathrm{ov}}^{\prime}=0.25 ; \mathbf{b} \tau_{o} / \sigma_{\mathrm{ov}}^{\prime}=0.10$ and $\tau_{\mathrm{c}} / \sigma_{\mathrm{ov}}^{\prime}=0.20$; $\mathbf{c} \tau_{o} / \sigma_{\mathrm{ov}}^{\prime}=0.05$ and $\tau_{\mathrm{c}} / \sigma_{\mathrm{ov}}^{\prime}=0.20 ; \mathbf{d} \tau_{o} / \sigma_{\mathrm{ov}}^{\prime}=0.10$ and $\tau_{\mathrm{c}} / \sigma_{\mathrm{ov}}^{\prime}=0.15 ; \mathbf{e} \tau_{o} / \sigma_{\mathrm{ov}}^{\prime}=0.0$ and $\tau_{\mathrm{c}} / \sigma_{\mathrm{ov}}^{\prime}=0.15 ; \mathbf{f} \tau_{o} / \sigma_{\mathrm{ov}}^{\prime}=0.20$ and $\tau_{\mathrm{c}} / \sigma_{\mathrm{ov}}^{\prime}=0.10$

shear stress. From this analysis, the following formulation was proposed,

$\frac{\Delta u}{\sigma_{\mathrm{ov}}^{\prime}}=a_{1}\left(\frac{\tau_{o}}{\sigma_{\mathrm{ov}}^{\prime}}-\frac{\tau_{\mathrm{c}}}{\sigma_{\mathrm{ov}}^{\prime}}\right)\left(e_{o}-\bar{e}\right)+\exp \left(\beta_{0}+\frac{\beta_{1}}{\frac{\tau_{\mathrm{c}}}{\sigma_{\mathrm{ov}}}}\right)$

where $\Delta u$ is the pore-water generation, $\sigma_{\text {ov }}^{\prime}$ effective vertical stress "in situ," $\tau_{o}$ initial shear stress, $\tau_{\mathrm{c}}$ cyclic shear stress, $e_{o}$ initial void ratio, $\bar{e}$ average void ratio, $a_{1}, \beta_{0}, \beta_{1}$ empirical constants.

The best fit obtained for all available data has correlation of $R^{2}=85 \%$, for the empirical constants $\beta_{0}=-0.063$ and $\beta_{1}=-0.041, a_{1}=2.61$ and $e_{o}=0.82$ as shown in Fig. 5.

\subsection{Mohr-Coulomb envelope}

The typical behavior observed in the 16 monotonic tests is shown in Fig. 6. The undrained shear strength and maximum pore-water pressure are developed for very large shear strains from a range of 12 to $22 \%$. Since the maximum values occur at very large shear strains, an analysis of the intrinsic resistant properties of the soil $(c, \varphi)$ was carried out for the 16 monotonic tests. Therefore, in an 
Table 1 Combination of stresses used and summary of the results of the tests analyzed in Figs. 3 and 4

\begin{tabular}{|c|c|c|c|c|c|c|c|}
\hline \multicolumn{2}{|c|}{ Reference } & \multirow{2}{*}{$\begin{array}{l}\tau_{o} \\
{[\%]}\end{array}$} & \multirow{2}{*}{$\begin{array}{l}\tau_{\mathrm{c}} \\
{[\%]}\end{array}$} & \multirow{2}{*}{$\begin{array}{l}N \\
\text { [cycles] }\end{array}$} & \multirow{2}{*}{$\begin{array}{l}\gamma_{p} \\
{[\%]}\end{array}$} & \multirow{2}{*}{$\begin{array}{l}\gamma_{c} \\
{[\%]}\end{array}$} & \multirow{2}{*}{$\begin{array}{l}u / \sigma_{\mathrm{ov}}^{\prime} \\
{[\%]}\end{array}$} \\
\hline Figure 3 & Figure 4 & & & & & & \\
\hline (a) & (a) & 0 & 25 & 15 & 8.9 & 17.8 & 72 \\
\hline (a) & - & 0 & 20 & 72 & 10.8 & 15.1 & 76 \\
\hline (a) & (e) & 0 & 15 & 500 & 11.4 & 15.4 & 84 \\
\hline (b) & & 5 & 25 & 15 & 7.3 & 12.9 & 71 \\
\hline (b) & (c) & 5 & 20 & 55 & 9 & 11.6 & 80 \\
\hline (c) & (b) & 10 & 20 & 28 & 15.5 & 7.7 & 75 \\
\hline (c) & (d) & 10 & 15 & 87 & 17.8 & 6.5 & 77 \\
\hline (d) & - & 15 & 15 & 1300 & 15.5 & 2 & 92 \\
\hline (d) & - & 15 & 10 & 1300 & 10.4 & 0.6 & 64 \\
\hline (e) & (f) & 20 & 10 & 1300 & 13.6 & 0.5 & 58 \\
\hline (e) & - & 20 & 5 & 1300 & 4.1 & 0.1 & 42 \\
\hline (f) & - & 25 & 5 & 1300 & 9.6 & 0.15 & 41 \\
\hline
\end{tabular}

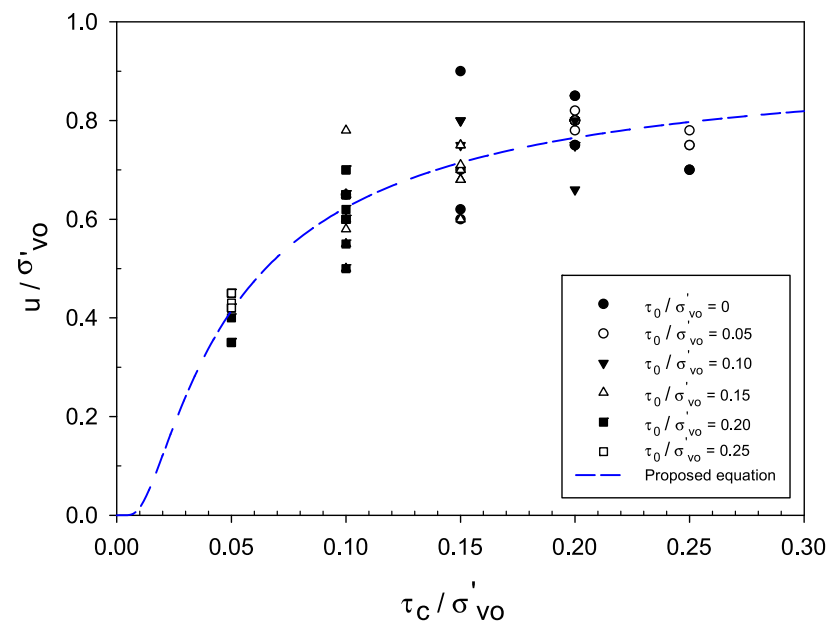

Fig. 5 Fit between estimated and actual pore-water pressure generation test data

approximate way it allows us to obtain the effective parameters of resistance to different shear strains that are required to work. For each level of shear strain, it obtains the mobilized shear strength parameters (cohesion and friction angle). These levels of shear strain are called allowable strains. That is, if it has a structure that does not admit a shear strain greater than $3 \%$, in this case, this value will be the maximum allowable strain for which there are mobilized cohesion and internal friction angle.

For each allowable strain, a Mohr-Coulomb equivalent envelope can be defined with the combination of shear and normal stresses that occur in the test. For example, for an allowable shear strain of $10 \%$, Fig. 6 shows that total normal stress of $311 \mathrm{kPa}$ and effective stress of 311-150 = $161 \mathrm{kPa}$ act for shear stress of $85 \mathrm{kPa}$. The 16 monotonic tests, carried out at different normal consolidation stresses, allow us to define the linear Mohr-Coulomb envelope (2) for the entire stress range. In this way, the equivalent cohesion and friction angle that limit a certain allowable strain are adjusted. The linear equation of the Mohr-Coulomb envelope is shown below

$\tau=A \cdot \sigma_{\mathrm{ov}}^{\prime}+B$

where the values of $A$ and $B$ correspond to $\left(B=c^{\prime}\right)$ and $\left(A=\tan \varphi^{\prime}\right)$. The equivalent effective parameters of cohesion and internal friction angle for each of the shear strains are included in Table 3 with their respective correlation value for each shear strain analyzed.

With values obtained from Table 2, Fig. 7 is obtained, which represents the behavior of each parameter as a function of the strain with its respective adjustment. In the cohesion case, the use of a linear fit was determined whose value is $R^{2}=94.2 \%$; it was considered a good fit and as simple as possible. The internal friction angle has an adjustment of $R^{2}=98.6 \%$ and is dependent on two adjustment coefficients. In both cases, an attempt was made to obtain the best possible fit, which is as simple as possible and passes through the origin of the graph. This is because posteriori could be easier to implement in a programming code for its numerical use.

Figure 7 shows the range of values that can be worked with as a function of shear strains. For the present work, it is chosen to limit the shear strain at $5 \%$, which corresponds to approximately $10 \mathrm{kPa}$ of cohesion and $20^{\circ}$ of internal friction angle like made-up values or equivalent parameters.

\section{Numerical methodology (FLAC2D)}

The numerical research was carried out under plane deformation conditions with the Mohr-Coulomb failure criterion, small strains, flow rule not associated with an angle of dilation equal to zero. Pane et al. [43] show that for friction angle values less than $25^{\circ}$, the non-associated flow rule has a very small effect while for higher values the effect is significant. Loukidis and Salgado [34] indicate that bearing capacity solutions with non-associated flow rule are more conservative than for associated flow rule. In this way, for the present work, the dilatation parameter was taken as a null value. Moreover, the numerical calculations were carried out with the use of a finite difference software FLAC2D [28]. FLAC2D includes an internal programming option (FISH), which allowed us to obtain or calculate the desired variables to control the analysis process. 


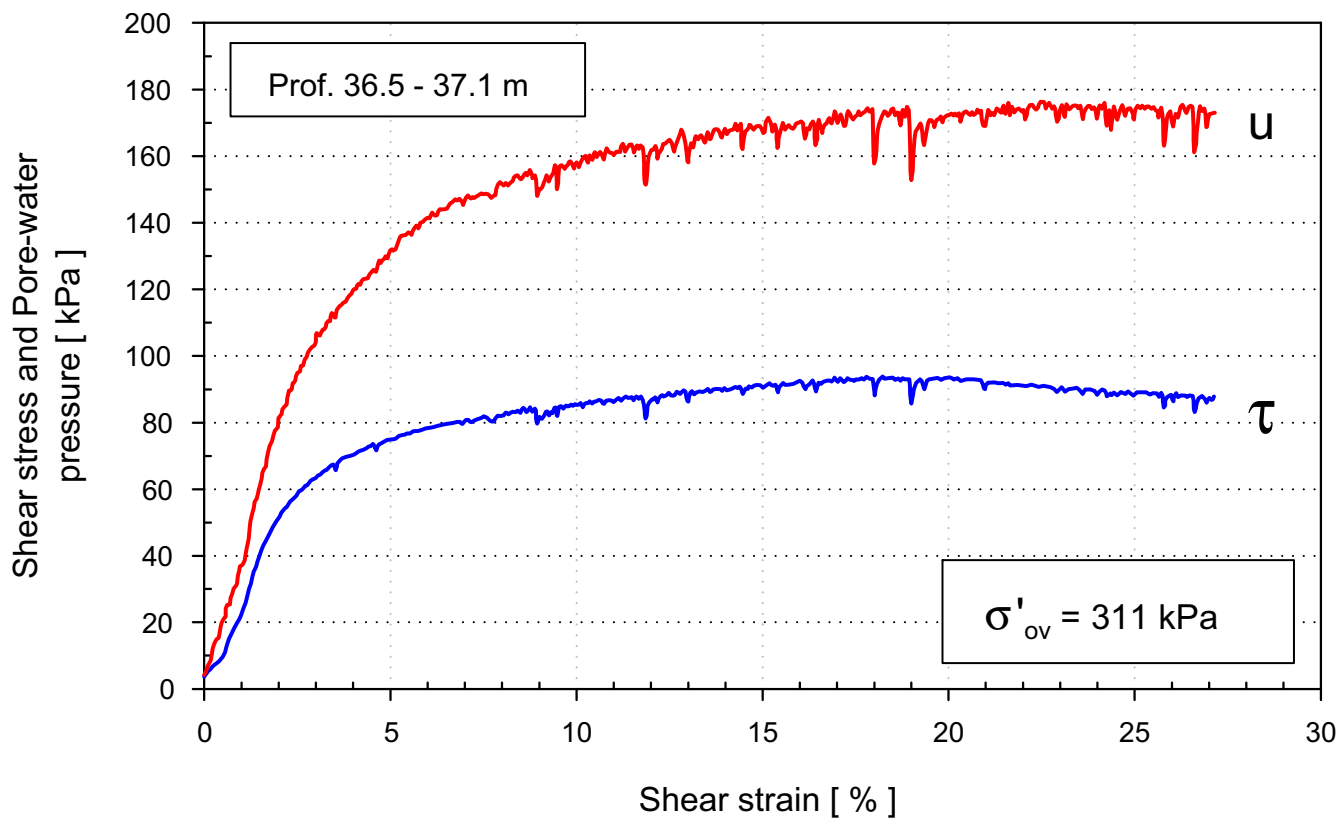

Fig. 6 Behavior of shear stress and pore-water pressure with the strain in the monotonic test

Table 2 Cohesion and internal friction angle values for each strain together with its correlation

\begin{tabular}{llll}
\hline$\gamma_{m}[\%]$ & $c^{\prime}[\mathrm{kPa}]$ & $\varphi^{\prime}\left[{ }^{\circ}\right]$ & $R^{2}$ \\
\hline 1 & 1.71 & 6.63 & 0.571 \\
3 & 6.21 & 15.82 & 0.791 \\
5 & 9.78 & 19.22 & 0.777 \\
7 & 15.18 & 20.29 & 0.720 \\
9 & 20.26 & 21.60 & 0.668 \\
11 & 18.81 & 22.83 & 0.731 \\
13 & 22.83 & 23.03 & 0.695 \\
15 & 25.25 & 23.97 & 0.684 \\
\hline
\end{tabular}

\subsection{Numerical model and soil properties}

The geometry and configuration of the model are shown in Fig. 8, in which the parameters of pore-water pressure and slip surface were considered to determine the size of the model. The optimal size was determined for a width of $(40 \cdot B)$ and a height of $(12 \cdot B)$, where $B$ is the width of the footing. To optimize and reduce model calculation time, a denser mesh was generated in the area of influence of porewater pressure and the slip surface. This zone has a total width of $(12 \cdot B)$, from the axis of the footing $(6 \cdot B)$ to each side and a height of $(6 \cdot B)$ down of the footing. On the other hand, at the ends of this zone and up to the contours of the model there is a less dense mesh that increases as it moves away from the zone of greater precision or more critical of the model.
The strip footing of width $\mathrm{B}$ is simulated as a rigid footing setting the displacements in $X$ and $Y$. To calculate the bearing capacity of the footing with FLAC2D, a vertical load must be applied to the footing incrementally; this load in the program is applied as a controlled downward velocity applied to each of the footing nodes. Meanwhile, the displacements of the footing are calculated as the integral of the velocity in each calculation step. In this way, it is important to know which the velocity of application load and the mesh size are most appropriate to the problem. For this, a convergence analysis was carried out that determined the optimal mesh size of $0.5 \mathrm{~m}$ and a load application velocity of $2.5 \times 10^{-7} \mathrm{~m} / \mathrm{step}$. The calculation of the bearing capacity in FLAC2D is given by the loaddisplacement methodology. A vertical downward velocity is applied across the width of the footing. This velocity is applied to the nodes of the footing; it is controlled and quantified as the vertical displacement for each calculation step that is performed. Finally, the application load is graphed with the displacement produced and the value is obtained when this load tends to be asymptotic at a constant value in the graph.

The soil used for the present work corresponds to a silty clay with low plasticity as previously described. The modulus of elasticity $(E)$ was determined to be $5 \mathrm{MPa}$ and the Poisson's Ratio ( $v$ ) to 0.25 from the soil studied of the Port of Barcelona [21]. These values expressed in volumetric modulus $(K)$ are $3.333 \mathrm{MPa}$ and a shear modulus $(S)$ $2 \mathrm{MPa}$. The parameters of cohesion and internal friction angle were determined from the Mohr-Coulomb envelope shown in Fig. 7. The parameters for a shear strain of $5 \%$ 
(a)

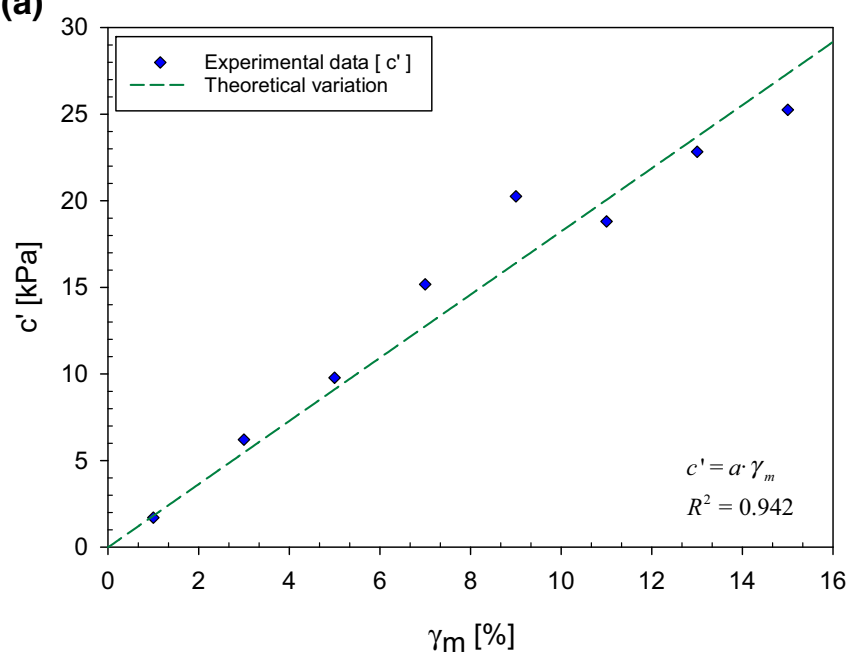

(b)

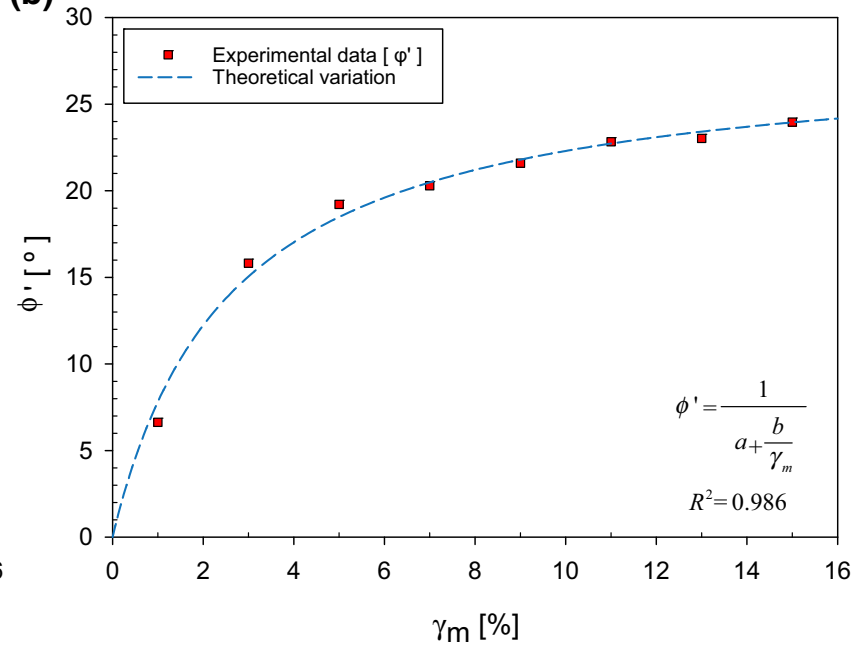

Fig. 7 Variation in cohesion and internal friction angle as a function of shear strain. a Variation in cohesion with shear strain; $\mathbf{b}$ variation internal friction angle with shear strain

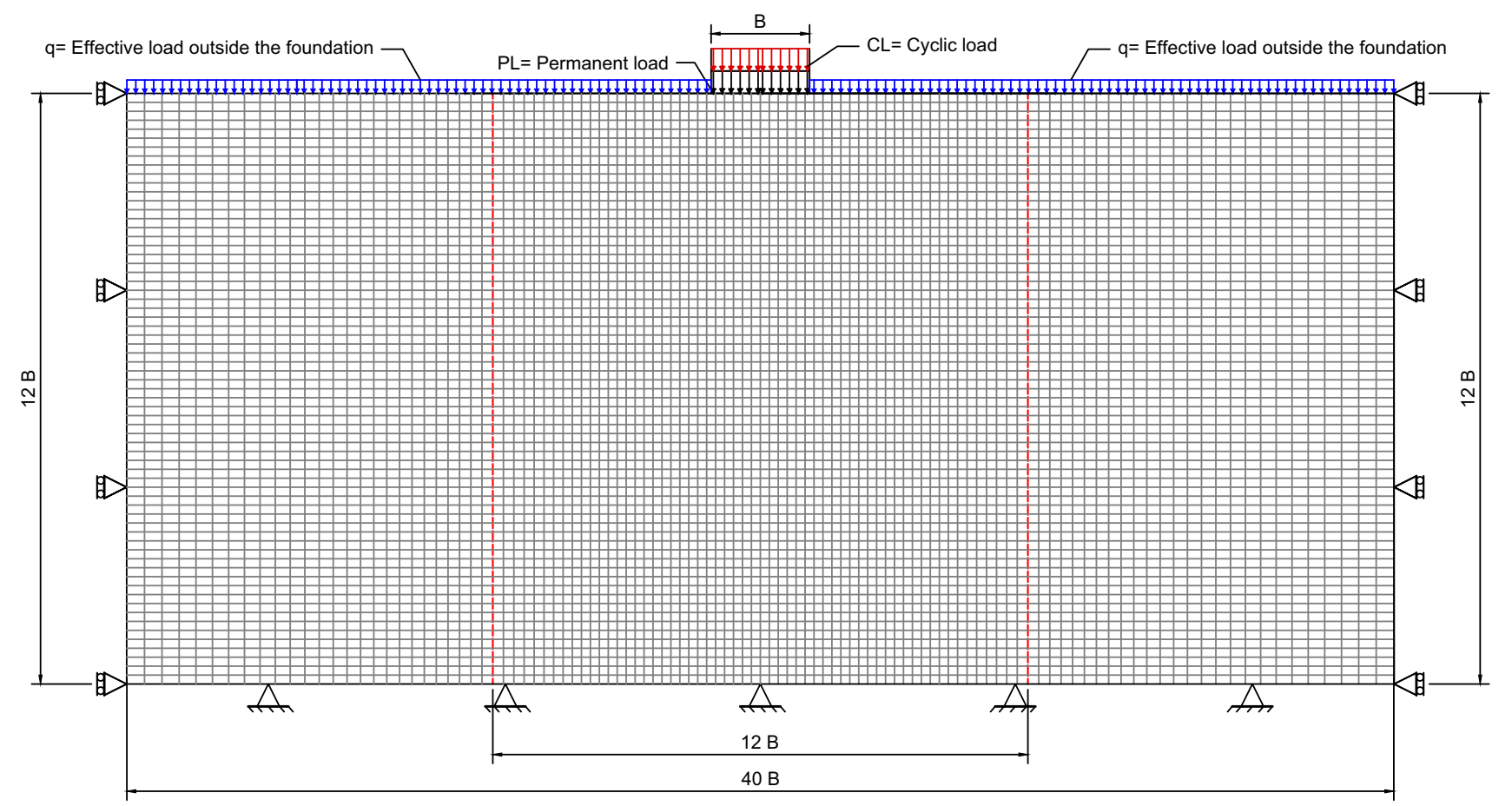

Fig. 8 Model and mesh type used in FLAC2D

were obtained, which gave a cohesion $(c)$ of $10 \mathrm{kPa}$, an internal friction angle $(\varphi)$ of $20^{\circ}$, and the angle of dilatation was assumed to be zero.

\subsection{Methodology of the calculation process}

The methodology for dynamic bearing capacity under cyclic load calculated process in FLAC2D consists of 6 calculation stages as described below
Stage 1: It consists of the calculation of the soil selftweight from the generation of the mesh, the boundary conditions of the model, and the definition of the soil and water properties.

Stage 2: Application and calculation of the permanent load (PL) on the footing and the effective load outside the foundation $(q)$.

Stage 3: Application and calculation of the cyclic load (CL), which is applied only on the footing. 
Step 4: Pore-water pressure generation calculation according to the adjusted formulation of experimental data.

Step 5: Equilibrium calculation of pore-water pressures and soil stresses to obtain effective soil stresses.

Stage 6: Calculation of the bearing capacity using the load-displacement method.

It is worth mentioning that the cyclic load within the numerical model was applied as a vertical load on the soil. The investigation works in the critical state and do not reproduce intermediate steps of increasing the pore-water pressure in each load cycle. Thus, the vertical load applied to the foundation represents the last application cycle (the critical state has already been reached), so this load produces an increase in vertical stress and an increase in shear stress at each point. The increase in pore-water pressure produced by the increase in cyclic shear stress at each point is indicated in the formulation of equation $1\left(\Delta u_{\text {eq. } 1}\right)$. And the increase of pore-water pressure due to vertical load is directly incremental stress value $\left(\Delta \sigma_{\mathrm{CL}}\right)$ produced by its cyclic load (undrained situation). Therefore, the final porewater pressure $\left(\Delta u_{\text {total }}\right)$ calculated in the step 4 is as follows:

$\Delta u_{\mathrm{total}}=\Delta u_{\mathrm{eq} .1}+\Delta \sigma_{\mathrm{CL}}$

Once the six calculation stages are completed, a verification is made under two verification criteria [44]. The first criterion refers to whether the bearing capacity calculated in the sixth stage is zero or close to zero, and the second criterion is that it must meet the Mohr-Coulomb failure criterion. If any of the two criteria are not met, it is necessary to return to stage three and modify the value of the higher or lower cyclic load as appropriate to perform the calculations again. This is an iterative process until the maximum value of the cyclic load on the footing is found.

Based on the detailed calculation process for the analysis, it was decided to carry out different combinations of footing width $(B)$, effective load outside the foundation $(q)$, and permanent load (PL) as indicated in Table 3.

Table 3 Numerical calculation cases in FLAC2D

\begin{tabular}{lllll}
\hline$c[\mathrm{kPa}]$ & $\varphi\left[^{\circ}\right]$ & $q \cdot\left(\% \cdot \mathrm{Ph}_{\mathrm{e}}\right)^{*}$ & $B \cdot(B)$ & $\mathrm{PL} \cdot\left(\% \mathrm{Ph}_{\mathrm{e}}\right)^{*}$ \\
\hline 10 & 20 & $0 ; 10 ; 20 ; 40$ & $0.5 ; 1 ; 2 ; 5$ & $1 ; 10 ; 25 ; 50 ; 75 ; 90$ \\
\hline
\end{tabular}

*The values of $(q)$ and (PL) are expressed as a percent of $\left(\mathrm{Ph}_{\mathrm{e}}\right)$

\section{Analysis and discussion of numerical results}

The analysis of the results of the dynamic bearing capacity of long-term shallow foundations in contractive cohesive soil is based on the behavior of the failure surface (Fig. 9) and on the generation of design charts proposed for different foundation widths shown in Fig. 10. The behavior of the failure wedge corresponds to a static case without generation of pore-water pressure and to dynamic cases in which different cyclic load values are applied until cyclic softening occurs and the soil fails. On the other hand, the charts correspond to 4 foundation widths $(0.5 \cdot B, B, 2 \cdot B, 5 \cdot B)$, with $\mathrm{B}$ being the reference width of the model shown in Fig. 8, which has a value of $5.5 \mathrm{~m}$. The charts correspond to cohesion soil parameters $(c)$ of $10 \mathrm{kPa}$, an internal friction angle of $(\varphi) 20^{\circ}$, and effective load outside the foundation $(q)$ of $0,0.1,0.2$, and 0.40 of the static bearing capacity $\left(\mathrm{Ph}_{\mathrm{e}}\right)$.

\subsection{Failure surface under cyclic load}

The analysis of the failure surface for different values of cyclic load applied to the model is shown in Fig. 9. Those failure surfaces correspond to the case of footing width (0.5 $\cdot B$ ), a permanent load (PL) of $50 \%$ of the bearing capacity static $\left(\mathrm{Ph}_{\mathrm{e}}=925 \mathrm{kPa}\right)$, and for an effective load outside the foundation $(q)$ of $20 \%$ of the initial bearing capacity of soil $\left(P h_{i}=390 \mathrm{kPa}\right)$. Analysis of the failure surfaces was carried out based on the failure surface for the soil in the static case and without pore-water pressure (case a). The variation in the applied cyclic load (CL) was for values of $1 \%$ (case b) and $10 \%$ (case c) of the static bearing capacity $\left(\mathrm{Ph}_{\mathrm{e}}\right)$ until reaching the maximum cyclic load value for which cyclic softening occurs (case d).

It is observed that both in the static case without porewater pressure (Fig. 9a) and in the dynamic cases (Fig. 9bd), the failure surface develops in the shallower meters (5 $\mathrm{m})$. However, it is particularly noteworthy that the zones of maximum affection tend to concentrate vertically under the edges of the footing as there is more cyclic load concerning to the total, as indicated by Budhu and Al-Karni [11]. This behavior shows how the generation of pore-water pressures in the soil produces a concentration of the failure surface, being localized in the proximity of the foundation.

\subsection{Full charts}

The charts shown in Fig. 10 represent a different foundation width for the same properties of soil with an imposed strain of 5\%. Every graph shown in Fig. 10 represents on the ordinate axis the dynamic bearing capacity ratio 
(a)

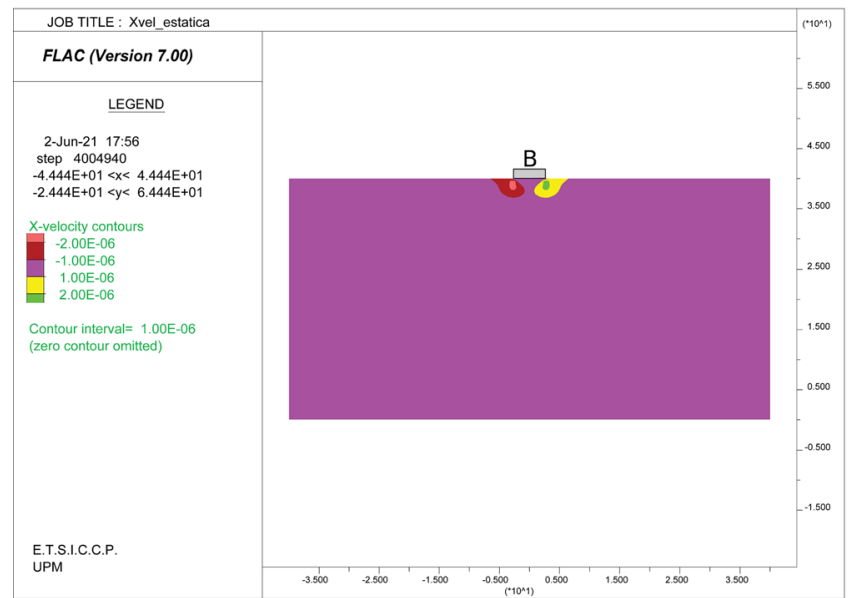

(c)

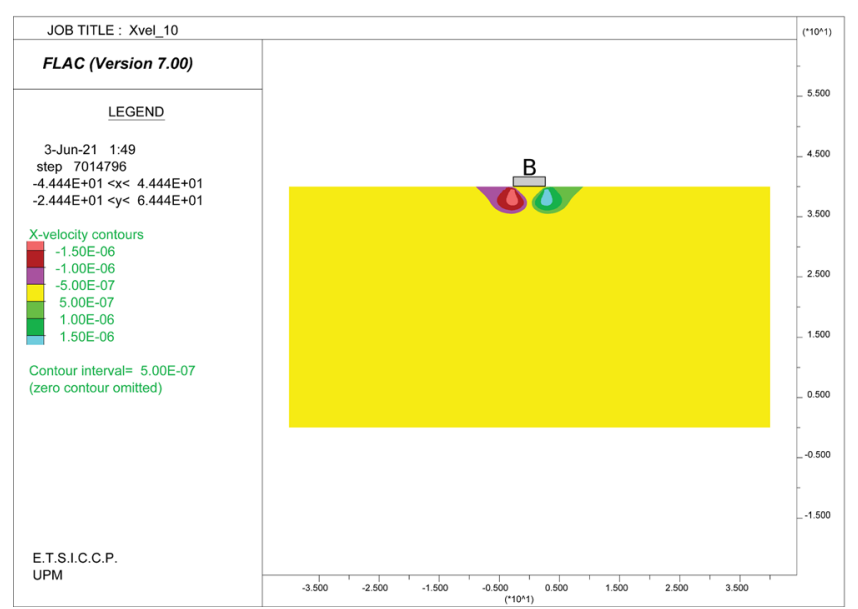

(b)

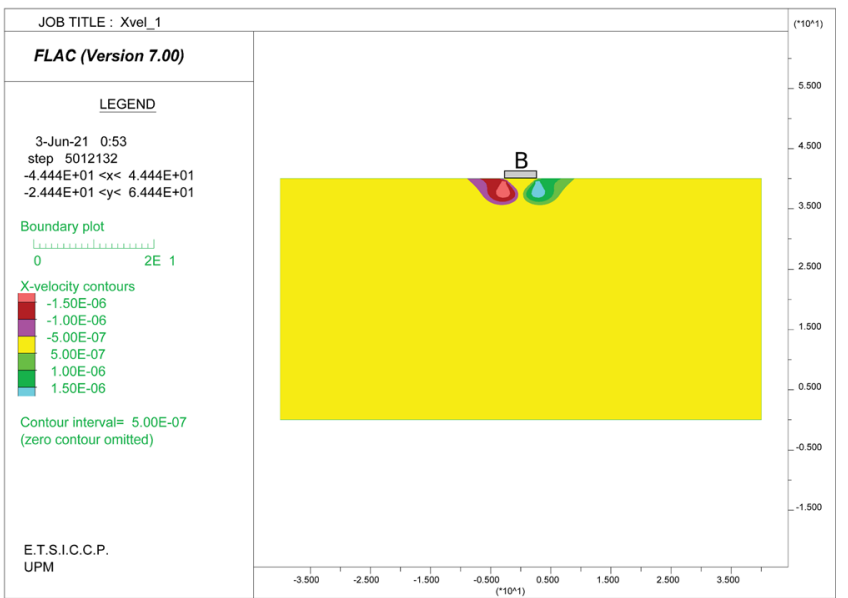

(d)

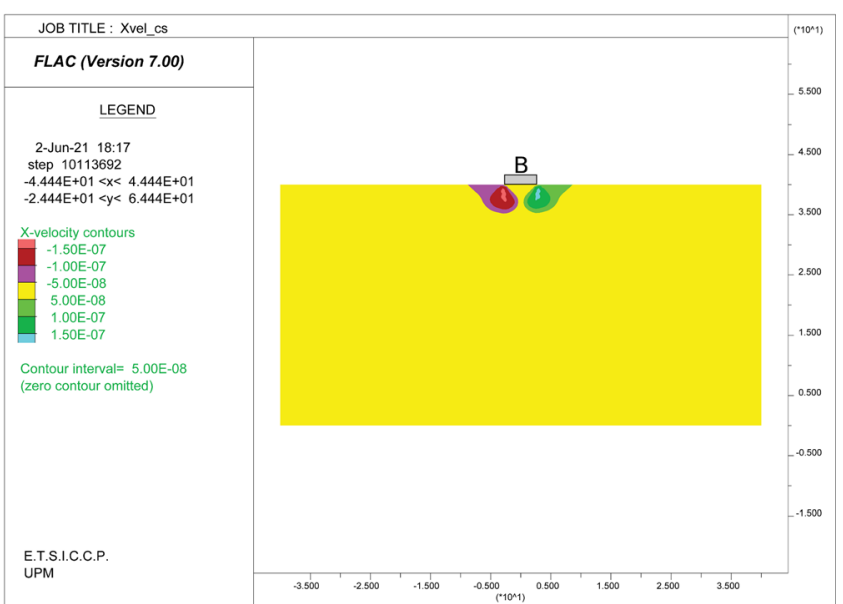

Fig. 9 Failure surfaces as a function of the variation in the cyclic load applied to the soil. a Static case; b $C L=0.01 \cdot \mathrm{Ph}_{\mathrm{e}} ; \mathbf{c} C L=0.10 \cdot \mathrm{Ph}_{\mathrm{e}}$; d cyclic softening case

expressed by $\left(\mathrm{Ph}_{\mathrm{d}} / \mathrm{Ph}_{\mathrm{e}}\right)$, while the abscissa represents on a logarithmic scale the permanent load normalized by the static bearing capacity $\left(\mathrm{PL} / \mathrm{Ph}_{\mathrm{e}}\right)$. Also, every graph represents a different foundation width, and every curve corresponds to an effective load value outside the foundation $(q)$. Part a) corresponds to a foundation width of $(0.5 \cdot B)$ in the numerical model, which, since it is symmetric, will be double in the real representation, which represents a width value of $5.5 \mathrm{~m}$. Part b) represents a width of $(1 \cdot B)$ or $11 \mathrm{~m}$ of foundation. Part c) has a width of $(2 \cdot B)$ which is $22 \mathrm{~m}$ and, finally, part d) with a width of $(5 \cdot B)$ which represents a value of $55 \mathrm{~m}$. In turn, these graphs have the effective load outside the foundation $(q)$ with values of $0,0.10,0.20$, and 0.40 of the value of the static bearing capacity $\left(\mathrm{Ph}_{\mathrm{e}}\right)$.

It should be mentioned that the charts were calculated for a long-term situation for the limited value of shear strain at $5 \%$. Values of cohesion $(c)$ and internal friction angle $(\varphi)$ were taken from the envelope defined previously in Fig. 7 for this shear strain value. The following sections analyze the results and the most influential parameters.

\subsection{Influence of the foundation width}

To analyze the influence of the foundation width, it will start to analyze Fig. 10. It can indicate that as the width of the foundation is greater, the dynamic bearing capacity ratio decreases in the charts. However, it should be considered that each chart is normalized by its static bearing capacity $\left(\mathrm{Ph}_{\mathrm{e}}\right)$ and each case has a different width footing, therefore a $\left(\mathrm{Ph}_{\mathrm{e}}\right)$ for each chart. It can also be observed that the values $\left(\mathrm{Ph}_{\mathrm{d}} / \mathrm{Ph}_{\mathrm{e}}\right)$ with self-weight of soil decrease with respect to the values weightless soil.

It is observed that there is a tendency to be greater the influence of the effective load outside the foundation when 

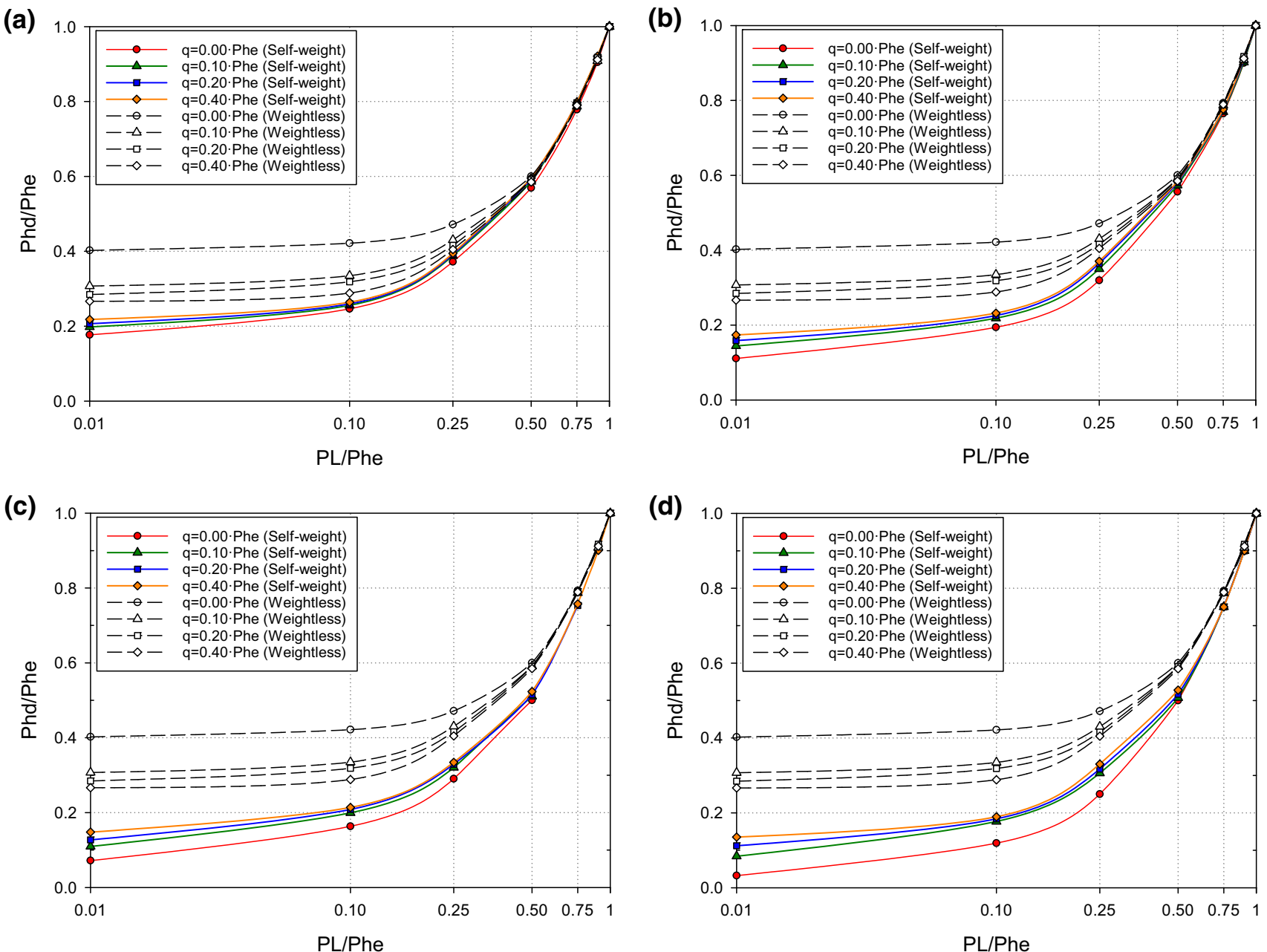

Fig. 10 Design charts proposed for different footing widths. a $0.5 \cdot B ; \mathbf{b} 1 \cdot B ; \mathbf{c} 2 \cdot B$; and $\mathbf{d} 5 \cdot B$. The reference width is $B=5.5 \mathrm{~m}$

the width of the foundation is greater. This shows the great influence that confining pressure has on the dynamic result. Thus, the greater the width of the foundation, the confinement of the interior points under the foundation is reduced, and therefore, there is a greater incidence of dynamic effects. It can also observe that for small values of $\mathrm{PL} / \mathrm{Ph}_{\mathrm{e}}$ there is a greater range of values of $\left(\mathrm{Ph}_{\mathrm{d}} / \mathrm{Ph}_{\mathrm{e}}\right)$ and that for larger values of $\left(\mathrm{PL} / \mathrm{Ph}_{\mathrm{e}}\right)$ at $50 \%$ the range decreases and tends to be almost the same values of $\left(\mathrm{Ph}_{\mathrm{d}} / \mathrm{Ph}_{\mathrm{e}}\right)$.

For understanding the charts and to observe the influence of the foundation width, it will do an example case in which the permanent load is the same $(\mathrm{PL}=100 \mathrm{kPa})$ and there will be no effective load outside the foundation ( $q=0 \mathrm{kPa}$ ). With the value of PL normalized by $\mathrm{Ph}_{\mathrm{e}}$ for each footing width, the value of the abscissa $\mathrm{PL} / \mathrm{Ph}_{\mathrm{e}}$ is obtained, and then, the curve corresponding to $q=0$ is chosen to find the value of the ordinate $\left(\mathrm{Ph}_{\mathrm{d}} / \mathrm{Ph}_{\mathrm{e}}\right)$. The summary of the values found for each chart is shown in Table 4.
Analyzing the results of Table 4 can indicate that there is a substantial difference in the value of the dynamic bearing capacity weightless and the values with self-weight of soil. Therefore, if it reviews the variation in the column $\mathrm{Ph}_{\mathrm{d}} / \mathrm{Ph}_{\mathrm{e}}$, it will see that the greater the width of the foundation, the smaller the value and that the greater value corresponds to the case weightless. However, these values are relative, since by multiplying them by their static bearing capacity values $\left(\mathrm{Ph}_{\mathrm{e}}\right)$, it obtained the dynamic

Table 4 Dynamic bearing capacity for various footing widths

\begin{tabular}{lllll}
\hline Description & Footing width $[\mathrm{m}]$ & $\mathrm{PL} / \mathrm{Ph}_{\mathrm{e}}$ & $\mathrm{Ph}_{\mathrm{d}} / \mathrm{Ph}_{\mathrm{e}}$ & $\mathrm{Ph}_{\mathrm{d}}[\mathrm{kPa}]$ \\
\hline $0.5 \cdot B$ & 5.5 & 0.256 & 0.37 & 142 \\
$1 \cdot B$ & 11 & 0.168 & 0.24 & 146 \\
$2 \cdot B$ & 22 & 0.108 & 0.17 & 158 \\
$5 \cdot B$ & 55 & 0.055 & 0.09 & 163 \\
Weightless & - & 0.714 & 0.75 & 105 \\
\hline
\end{tabular}


bearing capacity $\left(\mathrm{Ph}_{\mathrm{d}}\right)$. In the last column $\left(\mathrm{Ph}_{\mathrm{d}}\right)$, it can see that the values are inverted, denoting that the minimum value of $\left(\mathrm{Ph}_{\mathrm{d}}\right)$ corresponds to the case without self-weight and the highest value is for the largest footing width. Therefore, it can be asserted that the wider the footing, the greater the dynamic bearing capacity $\left(\mathrm{Ph}_{\mathrm{d}}\right)$.

\subsection{Influence of an effective load outside the foundation}

An analysis of the variation in the curves as a function of the effective load outside the foundation was carried out for the cases of $\mathrm{q}=0,10,20$, and $40 \%$ of the static bearing capacity $\left(\mathrm{Ph}_{\mathrm{e}}\right)$. In general, from Fig. 11 for $\left(P L / \mathrm{Ph}_{\mathrm{e}}\right)$ values greater than $75 \%$ there is little influence of the effective load outside the foundation. However, for values lower than $75 \%$ of $\left(P L / \mathrm{Ph}_{\mathrm{e}}\right)$ there is a considerable influence from the width of the foundation. This is because as there is more incidence of dynamic load, the more significant the confinement of the central points under the foundation becomes. Therefore, the greater width of the foundation affects less confinement of these points and therefore a lower dynamic resistance.

It can mention that curves with their self-weight of soil, as opposed to those weightless, have different behavior in terms of greater dynamic bearing capacity ratio. In the case of the weightless curves, the one with the greatest dynamic bearing capacity ratio is the one corresponding to $\left(q=0 \cdot \mathrm{Ph}_{\mathrm{e}}\right)$, unlike the self-weight of soil curves in which the highest corresponds to $\left(q=0.40 \cdot \mathrm{Ph}_{\mathrm{e}}\right)$. Therefore, the most critical case for self-weight curves is when there is no effective load outside the foundation. From this last analysis, it can be mentioned that it is closer to reality because the self-weight of the soil implies confinement.

For the cases of part a) that are without effective load outside the foundation $(q=0 \cdot P h e)$, it can indicate that the maximum value corresponds to the curve weightless and has a value of $P h_{d} / \mathrm{Ph}_{e}=0.40$ for $P L / \mathrm{Ph}_{e}=0.01$. If it (a)

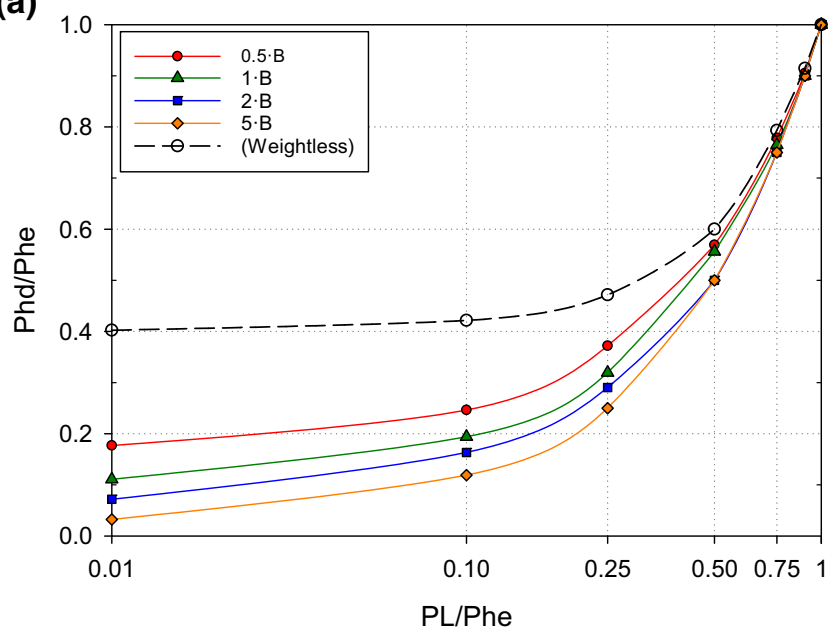

(c)

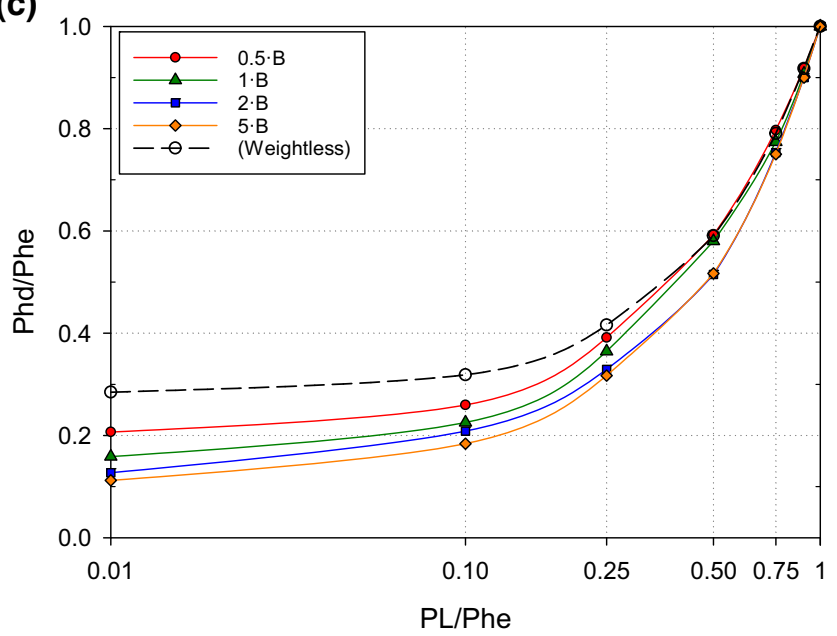

(b)

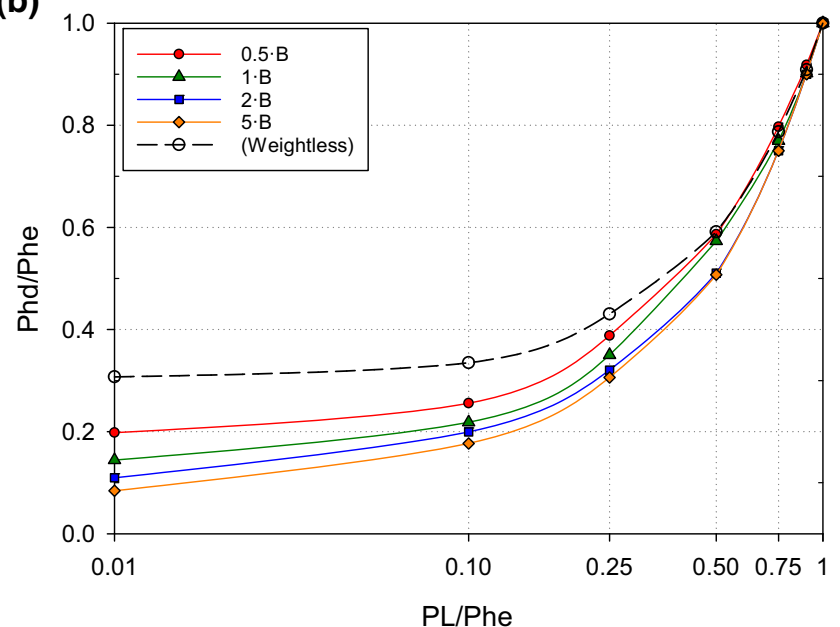

(d)

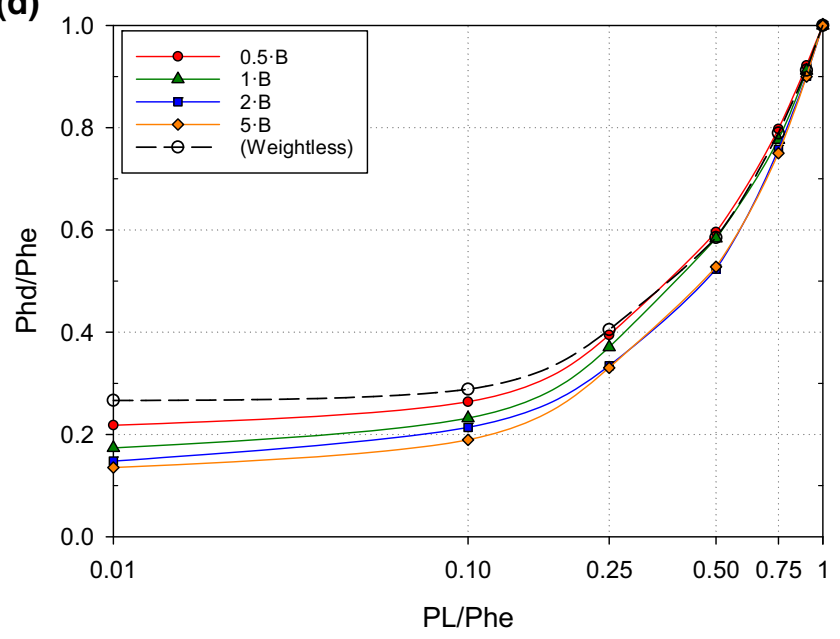

Fig. 11 Influence of the effective load outside the foundation. a $q=0 \cdot \mathrm{Ph}_{\mathrm{e}} ; \mathbf{b} q=0.10 \cdot \mathrm{Ph}_{\mathrm{e}} ; \mathbf{c} q=0.20 \cdot \mathrm{Ph}_{\mathrm{e}} ; \mathbf{d} q=0.40 \cdot \mathrm{Ph}_{\mathrm{e}}$ 
observes the curves with self-weight, the maximum value is for $(0.5 \cdot B)$ with a value of $\mathrm{Ph}_{\mathrm{d}} / \mathrm{Ph}_{\mathrm{e}}=0.18$, and when the width of the foundation increases, it decreases the value of dynamic bearing capacity ratio to $\mathrm{Ph}_{\mathrm{d}} / \mathrm{Ph}_{\mathrm{e}}=0.03$ for a width of $(5 \cdot B)$. Therefore, for an effective load situation outside the foundation with a null value, the maximum difference between the curve weightless and with selfweight is $22 \%$ in global terms. The tendency of the parts b), c) and d) is like the a) with the difference that decreases the variation between the curve weightless with the curve selfweight. This can be observed in part d) when the difference is reduced to a value of 5\% in global terms. On the other hand, it can be indicated from the curves with self-weight that the maximum variation occurs for a value of $P L / \mathrm{Ph}_{\mathrm{e}}=$ 0.01 with a value of $15 \%$ between the curves that correspond to a width of $0.5 \cdot B$ and the curve for a width $5 \cdot B$, while the minimum variation will be in part d) with a value of $8 \%$ that corresponds to the curve of $0.5 \cdot B$ with a value of $\mathrm{Ph}_{\mathrm{d}} / \mathrm{Ph}_{\mathrm{e}}=0.22$ and the curve $5 \cdot B$ with a value of $\mathrm{Ph}_{\mathrm{d}} / \mathrm{Ph}_{\mathrm{e}}=0.14$.

If it takes a practical case of $\mathrm{PL} / \mathrm{Ph}_{\mathrm{e}}=0.01 \cdot \mathrm{Ph}_{\mathrm{e}}$ and graphically analyzes the influence of the effective load outside the foundation as a function of the width of the footing, it will have Fig. 12. In this graph, it can analyze how the variation is for each case; it can see that the dynamic bearing capacity ratio varies very little when there is no effective load outside the foundation. On the contrary, it tends to decrease the value of the dynamic bearing capacity ratio the greater the width of the footing. But, when the value of the effective load outside the foundation and the width of the footing is increased, the value of the dynamic bearing capacity ratio increases its value considerably.

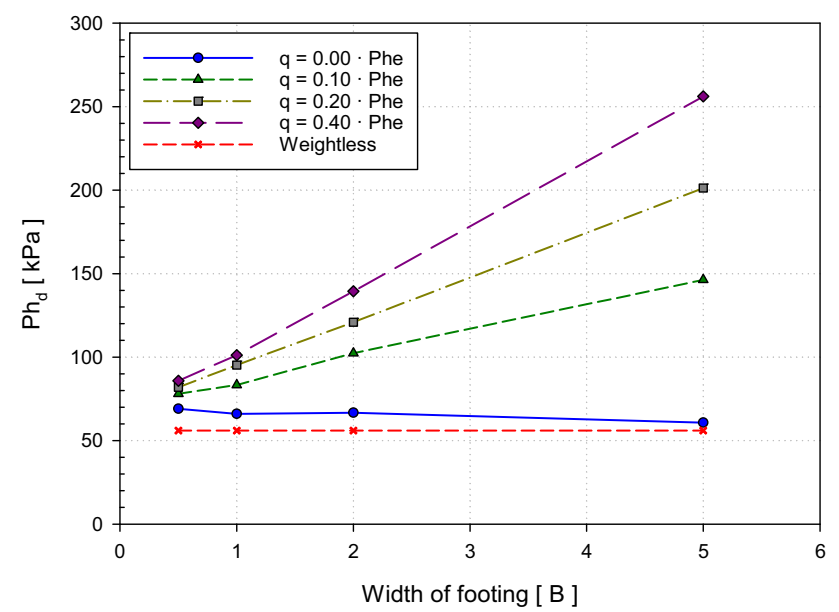

Fig. 12 Variation in the dynamic bearing capacity as a function of the footing width

\section{Application to a real case}

As an application of the charts proposed in Fig. 10, a comparison is made with a historical case such as the Carrefour Shopping Center.

\subsection{Description}

The historical case of the Carrefour Shopping Center $[10,36,57]$ is located in the northwest of Turkey and suffered the Kocaeli earthquake of 7.4 magnitudes in 1999. The specific area for the analysis corresponds to an area that was under construction and had areas with improvements in the soil and others that were not improved.

The stratigraphic profile is shown in Fig. 13 consisting of marine sediments with alternating layers of clay, silt, and sand. The water table is $2 \mathrm{~m}$ deep, and there are two recent fills. The first one is called "new fill" consisting of a $3.3 \mathrm{~m}$ preload clayey gravel fill (GC) above the initial zero levels and another $2 \mathrm{~m}$ fill "old fill" below the zero levels consisting of a medium dense clay gravel soil (GC). Further down, it has $5.2 \mathrm{~m}$ of saturated fine-grained soil (ML/ CL) with soft to firm resistance and low plasticity and then the presence of a layer of silty sand (SP/SM) of loose to medium density with a depth of $1.2 \mathrm{~m}$. Below it is a very fine layer of $0.90 \mathrm{~m}$ of fine-grained soil (ML/CL) followed by the clay of high plasticity $(\mathrm{CH})$ of medium-high stiffness and that extends more than $35 \mathrm{~m}$ deep [10].

The behavior of clays and silts of low plasticity under monotonic and cyclic undrained load can vary depending on a very small range of plasticity index (PI). If a finegrained soil has a PI greater than or equal to 7 , its behavior will be that of a clayey soil or, otherwise, of sandy soil [9]. Boulanger and Idriss [10] indicate that normally or slightly consolidated clays generally tend to have higher water

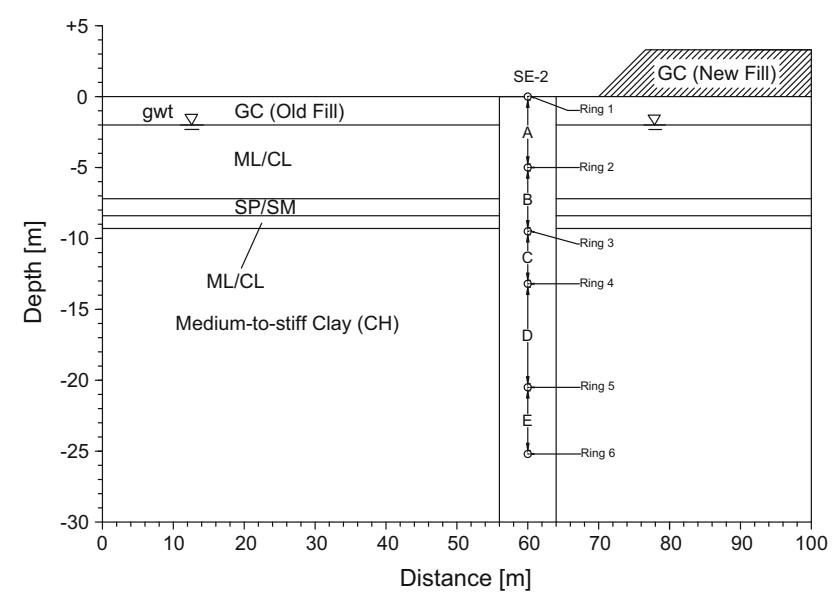

Fig. 13 Profile of the soil near the extensometer (SE2) in the Carrefour Shopping Center (adapted from [36]) 
Table 5 Properties of the soil of the Carrefour Shopping Center profile

\begin{tabular}{lllll}
\hline Soil layer & Depth $[\mathrm{m}]$ & PI & $S_{u}\left[\mathrm{kN} / \mathrm{m}^{3}\right]$ & $\gamma\left[\mathrm{kN} / \mathrm{m}^{3}\right]$ \\
\hline Existing Fill (GC) & $0-2$ & - & - & 20 \\
Clayey silts (ML/CL) & $2-7.2$ & 10 & 25 & 18.6 \\
Silty sand (SM) & $7.2-8.4$ & - & - & 20 \\
Clayey silts (ML/CL) & $8.4-9.3$ & 11 & 31 & 18.6 \\
High plasticity clay (CH) & $9.3-35$ & 37 & 35 & 16.4 \\
\hline
\end{tabular}

The overload of the new fill of $3.3 \mathrm{~m}$ has a total unit weight of $20 \mathrm{kN} /$ $\mathrm{m}^{3}$

content, high liquidity index values, and greater sensitivity; therefore, they are more likely to lose strength during an earthquake. The main geomechanical properties are shown in Table 5, and if it observes the plasticity index, its behavior according to Boulanger and Idriss [9] would correspond to that of clay soil, and therefore, it is suitable to carry out in our analysis.

\subsection{Case study development}

Using the methodology described in this research, the case study can be solved using the proposed chart, generating a model of the case in a simplified way as shown in Fig. 14. In this model, it can be assumed that the effective load outside the foundation $(q)$ has a value of $40 \mathrm{kN} / \mathrm{m}$, which corresponds to $2 \mathrm{~m}$ of "old fill." There is a permanent load
(PL) of $106 \mathrm{kN} / \mathrm{m}$ distributed over the application width of the "new fill," which has a height of $3.3 \mathrm{~m}$ from the new fill and $2 \mathrm{~m}$ from the old fill. According to what was mentioned by [9], the behavior of the soil corresponds to clay soil because it has a plasticity index greater than 7 . This leads to consider a single cohesive soil susceptible to cyclic softening due to the accumulation of pore-water pressure produced by the cyclic load of the earthquake. The geomechanical properties for the elastic numerical model correspond to a volumetric modulus $(K)$ equal to 3.333 $\mathrm{MPa}$, a shear modulus $(S)$ of $2 \mathrm{MPa}$, a unit weight $(\gamma)$ of $19.62 \mathrm{kN} / \mathrm{m}^{3}$, a cohesion $(c)$ of $10 \mathrm{kPa}$, and an internal friction angle of $(\varphi) 20^{\circ}$. It is worth mentioning that the cohesion and internal friction angle values correspond values to the made-up values for it can be analyzed from the charts and do not correspond to the soil of the case under study.

A very simplified way to calculate the cyclic shear stress produced by an earthquake is that proposed by Seed and Idriss [52]. This is based on the simplified representation of the distribution of shear stress with depth in a column of soil as can be seen:

$$
\tau_{\text {eff }}=0.65 \cdot \frac{a_{\mathrm{max}}}{g} \cdot \sigma_{\mathrm{vo}} \cdot r_{\mathrm{d}}
$$

where $\tau_{\text {eff }}=$ effective cyclic shear stress, $a_{\max }=$ peak ground acceleration, $g=$ acceleration of gravity, $\sigma_{\mathrm{vo}}=$ in situ vertical total stress, $r_{\mathrm{d}}=$ stress reduction factor.

The depth of analysis at which the collapse occurs is 10 $\mathrm{m}$ below the fill according to Tsai et al. [57]. Using

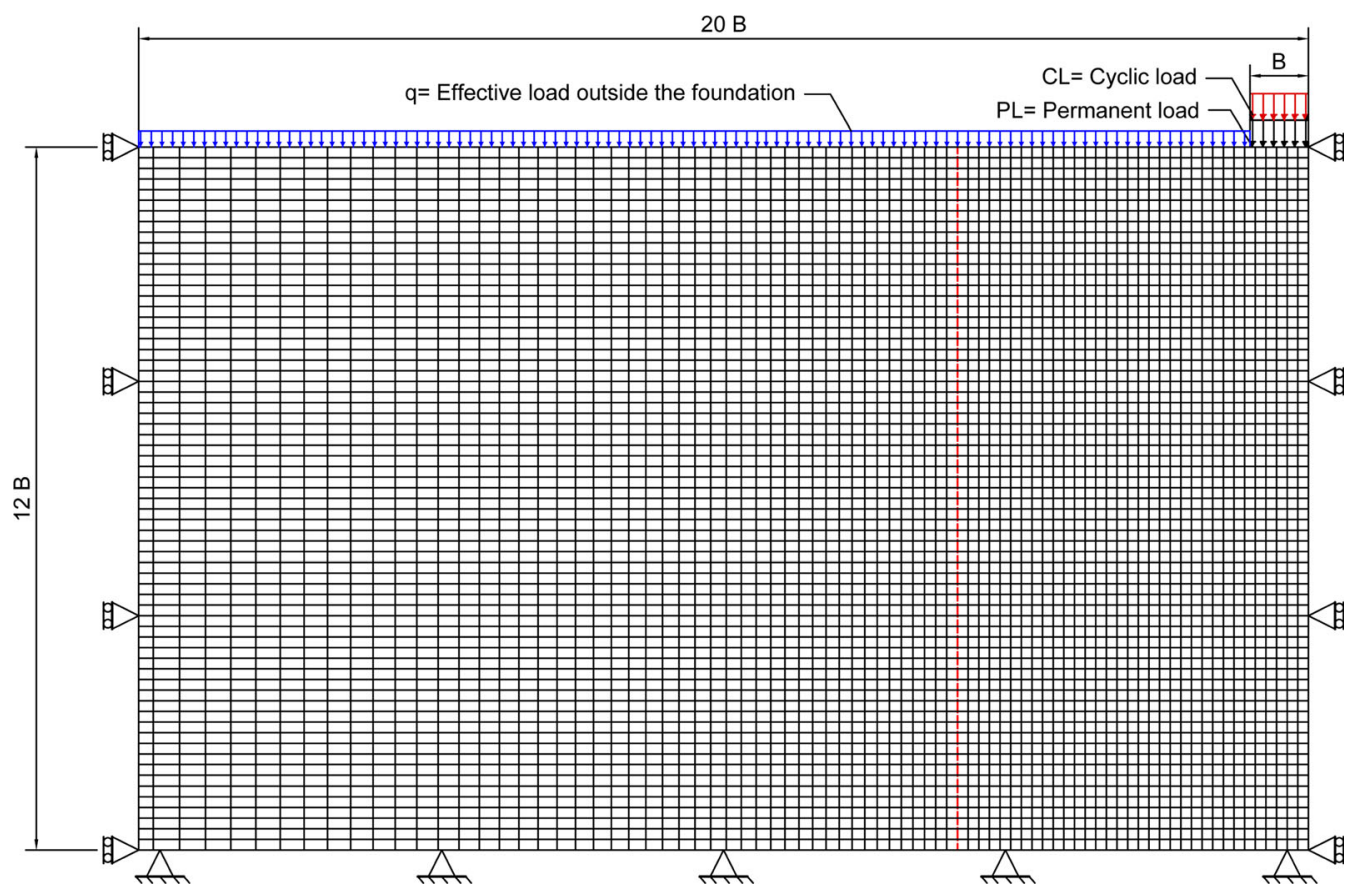

Fig. 14 A simplified model for the Carrefour case study 
Table 6 Cyclic load values obtained from the chart (Fig. 10)

\begin{tabular}{lll}
\hline Description & Footing width $[\mathrm{m}]$ & Cyclic Load $(\mathrm{CL})[\mathrm{kN} / \mathrm{m}]$ \\
\hline $0.5 \cdot B$ & 5.5 & 53.17 \\
$1 \cdot B$ & 11 & 60.73 \\
$2 \cdot B$ & 22 & 64.84 \\
$5 \cdot B$ & 55 & 67.94 \\
Weightless & - & 52.54
\end{tabular}

formulation (3), an average shear stress value $\left(\tau_{\mathrm{av}}\right)$ of 19.7 $\mathrm{kPa}$ was obtained. Then, to obtain the value of the external load (CL) that produces average shear stress of $19.7 \mathrm{kPa}$ in the $10 \mathrm{~m}$ of influence, it can be calculated from an approximation applying the theory of elasticity and distributed in the application width; it has a value of $56 \mathrm{kN} / \mathrm{m}$. This is the cyclic surface load value that produces the same shear stress increase in the study area due to the earthquake.

Table 6 shows the cyclic load values obtained for different foundation widths. If it compares the theoretically obtained value of $56 \mathrm{kN} / \mathrm{m}$, it is observed that it is within the range of values obtained from the proposed charts. In turn, it can appreciate the influence of the foundation width under cyclic load. This means that the greater the width of the foundation, the greater cyclic load the same soil can resist. On the other hand, it is also appreciated that not taking into account the self-weight of the soil is a very conservative way when designing a foundation under cyclic load. This result shows that the procedures together with the charts can be used practically and simply as a first approximation to detect cyclic softening in soil.

However, a small comparison was made with the method of Tsai et al. [57]. This section indicates that in both cases cyclic softening occurs for a similar shear stress on the ground, although the analysis methods are different. Tsai et al. [57] use a strain-based approach; this method estimates cyclic softening and associated strength loss given the effective of shear strain amplitude and the equivalent number of uniform strain cycles. On the other hand, our work proposes a calculation methodology in separate steps ( 6 calculation stages). One of these stages is made up of the calculation of the pore pressure generation by incorporating a formulation that depends on the combination of initial and cyclic shear stresses, and the void ratio.

\section{Conclusions}

The evaluation of the long-term dynamic bearing capacity of shallow foundations on a contractive cohesive soil was carried out satisfactorily. Based on a proposed methodology, design charts were generated under the influence of the self-weight of the soil or width of the footing and the effective load outside the foundation. The main aspects and conclusions are the following:

- Based on the experimental data of monotonic simple shear, a Mohr-Coulomb envelope could be obtained for the determination of the cohesion and friction angle parameters, dependent on shear strains. If it observes the variation in cohesion with strain, it can see that the variation tends to be linear. For its part, the internal friction angle for strains from 0 to $5 \%$ has a large increase varying from $0^{\circ}$ to $20^{\circ}$, then it becomes a more constant increase with little variation, so for strains of 5 to $15 \%$ only varies from $20^{\circ}$ to $25^{\circ}$.

- Analyzing the results of cyclic simple shear tests, it can indicate that for initial shear stress $\left(\tau_{\mathrm{c}} / \sigma_{\mathrm{ov}}^{\prime}\right)$ equal to 0,5 and $10 \%$; the number of cycles $(N)$ decreases when the cyclic shear stress $\left(\tau_{\mathrm{c}} / \sigma_{\mathrm{ov}}^{\prime}\right)$ increases to reach the soil failure. But for initial shear stresses of 15,20 , and $25 \%$, it was reached maximum value of 1300 cycles that was limited in the tests.

- The influence of the initial shear stress $\left(\tau_{o} / \sigma_{\text {ov }}^{\prime}\right)$ has two behaviors; first, for values of 0,5 , and $10 \%$, the higher cyclic shear stress $\left(\tau_{\mathrm{c}} / \sigma_{\mathrm{ov}}^{\prime}\right)$ corresponds to lower the number of cycles $(N)$ at which the soil fails. Moreover, pore-water pressure generation at the moment of soil failure was constant at a critical value of around $75 \%$. The second is for values of 15 and $20 \%$, the number of cycles is high and when the higher the cyclic shear stress corresponds to the greater pore-water pressure at the moment of soil failure.

- If it analyzes the stress-strain shear relationship, it is observed that the total shear strain has a cyclic component $\left(\gamma_{c}\right)$ and a permanent component $\left(\gamma_{p}\right)$. For initial shear stress values of 0,5 , and $10 \%$, a higher the cyclic shear stress corresponds to a lower the permanent strain $\left(\gamma_{p}\right)$ that accumulates with the cycles, but greater the cyclic strain $\left(\gamma_{c}\right)$. On the other hand, for initial shear stress values of 15 and $20 \%$, there is a trend toward greater cyclic shear stress, greater permanent strain, and greater cyclic strain.

- The charts of Fig. 10 were presented to determine the dynamic bearing capacity of shallow foundations in contractive cohesive soil for made-up values of $10 \mathrm{kPa}$ of cohesion and $20^{\circ}$ of internal friction angle. These made-up values were determined by limiting the shear strain to 5\% according to Fig. 7. However, it believes that the methodology proposed in this paper is a contribution that can be applied in the same way for situations where there are experimental data and the empirical constant of equation 1 can be obtained. On the other hand, if a cohesive soil is analyzed within the 
range of parameters studied in this research, it will also be possible to use these charts for a wide range of applied stresses.

- The influence of the width of the foundation in the calculation of the dynamic bearing capacity expresses that the greater the width of the foundation tends to be greater than the value of the dynamic bearing capacity in global terms as shown in Fig. 10. However, in specific terms or multiplied by their respective static bearing capacity, the most conservative values correspond to the curves with weightless, while the curves with self-weight tend to have less dynamic load capacity at the greater width of the foundation.

- The influence of the effective load outside the foundation is given by a decrease in the value of $\left(\mathrm{Ph}_{d} / \mathrm{Ph}_{e}\right)$ in each graph of Fig. 11, which indicates that in global terms the greater the width of the foundation the lower the dynamic bearing capacity. However, in specific terms, it can verify that the greater the foundation width for the same effective load outside the foundation corresponds to higher values of dynamic bearing capacity.

- The susceptibility to cyclic softening was demonstrated by the methodology and chart proposed for the Carrefour documented real case, showing that the charts and the methodology can be used practically and simply to detect cyclic softening in a contractive cohesive soil.

Open Access This article is licensed under a Creative Commons Attribution 4.0 International License, which permits use, sharing, adaptation, distribution and reproduction in any medium or format, as long as you give appropriate credit to the original author(s) and the source, provide a link to the Creative Commons licence, and indicate if changes were made. The images or other third party material in this article are included in the article's Creative Commons licence, unless indicated otherwise in a credit line to the material. If material is not included in the article's Creative Commons licence and your intended use is not permitted by statutory regulation or exceeds the permitted use, you will need to obtain permission directly from the copyright holder. To view a copy of this licence, visit http://creativecommons. org/licenses/by/4.0/.

Funding Open Access funding provided thanks to the CRUE-CSIC agreement with Springer Nature.

\section{References}

1. Ajmera B, Brandon T, Tiwari B (2017) Influence of index properties on shape of cyclic strength curve for clay-silt mixtures. Soil Dyn Earthq Eng 102:46-55. https://doi.org/10.1016/j.soil dyn.2017.08.022

2. Alonso E, Gens A (2007) The soft foundation soils of new breakwaters at the port of Barcelona. In: Press I (ed) Proceedings of the 14th European conference on soil mechanics and geotechnical engineering, Madrid, pp 1765-1770
3. Anastasopoulos I, Gazetas G, Loli M, Apostolou M, Gerolymos N (2010) Soil failure can be used for seismic protection of structures. Bull Earthq Eng 8:309-326. https://doi.org/10.1007/ s10518-009-9145-2

4. Andersen KH (2009) Bearing capacity under cyclic loading: offshore, along the coast, and on land. The 21st Bjerrum Lecture presented in Oslo, 23 November 2007 1. Can Geotech J 46:513-535. https://doi.org/10.1139/T09-003

5. Barrios G, Larkin T, Chouw N (2020) Influence of shallow footings on the dynamic response of saturated sand with low confining pressure. Soil Dyn Earthq Eng. https://doi.org/10.1016/ j.soildyn.2019.105872

6. Beygi M, Keshavarz A, Abbaspour M, Vali R, Saberian M, Li J (2020) Finite element limit analysis of the seismic bearing capacity of strip footing adjacent to excavation in $\mathrm{c}-\phi$ soil. Geomech Geoeng 00(00):1-14. https://doi.org/10.1080/ 17486025.2020.1728396

7. Bjerrum L, Landva A (1966) Direct simple-shear tests on a Norwegian quick clay. Géotechnique 16:1-20

8. Booker JR, Rahman MS, Bolton Seed H (1976) GADFLEA: a computer program for the analysis of pore pressure generation and dissipation during cyclic or earthquake loading. Technical report

9. Boulanger RW, Idriss IM (2006) Liquefaction susceptibility criteria for silts and clays. $J$ Geotech Geoenviron Eng 132:1413-1426

10. Boulanger RW, Idriss IM (2007) Evaluation of cyclic softening in silts and clays. J Geotech Geoenviron Eng 133:641-652

11. Budhu M, Al-Karni A (1993) Seismic bearing capacity of soils. Geotechnique 43(1):181-187. https://doi.org/10.1680/geot.1994. 44.1.185

12. Byrne PM (1991) A cyclic shear-volume coupling and pore pressure model for sand. In: Second international conference on recent advances in geotechnical earthquake engineering and soil dynamic, pp 47-55

13. Cascone E, Casablanca O (2016) Static and seismic bearing capacity of shallow strip footings. Soil Dyn Earthq Eng 84:204-223

14. Choudhury D, Subba Rao KS (2005) Seismic bearing capacity of shallow strip footings. Geotech Geol Eng 23(4):403-418. https:// doi.org/10.1007/s10706-004-9519-9

15. Chu DB, Stewart JP, Boulanger RW, Lin PS (2008) Cyclic softening of low-plasticity clay and its effect on seismic foundation performance. $\mathrm{J}$ Geotech Geoenviron Eng 134(November):1595-1608

16. Conti R (2018) Simplified formulas for the seismic bearing capacity of shallow strip foundations. Soil Dyn Earthq Eng 104:64-74

17. Dobry R, Ladd R, Yokel F, Chung R, Powell D (1982) Prediction of pore water pressure buildup and liquefaction of sands during earthquakes by the cyclic strain method. National Bureau of Standards, Gaithersburg

18. Galindo-Aires R, Lara-Galera A, Melentijevic S (2019) Hysteresis model for dynamic load under large strains. Int J Geomech 19(6):1-13. https://doi.org/10.1061/(ASCE)GM.1943-5622. 0001428

19. Galindo-Aires R, Lara-Galera A, Patiño Nieto H (2020) Hysteresis model for soft cohesive soils under combinations of static and cyclic shear loads. Int J Geomech 20(10):04020165. https:// doi.org/10.1061/(ASCE)GM.1943-5622.0001793

20. Galindo Aires RÁ (2010) Análisis, Modelización e Implementación Numérica del Comportamiento de Suelos Blandos ante la combinación de Tensiones Tangenciales Estáticas y Cíclicas. $\mathrm{PhD}$ thesis, Universidad Politecnica de Madrid

21. Gazetas G, Apostolou M, Anastasopoulos J (2003) Seismic uplifting of foundations on soft soil, with examples from 
Adapazari (Izmit 1999 earthquake). In: BGA international conference on foundations: innovations, observations, design and practice. Thomas Telford Publishing, Dundee, pp 37-49

22. Green RA, Mitchell JK, Polito CP (2000) An energy-based excess pore pressure generation model for cohesionless soils. In: AAB Publishers (ed) Proceedings of the John Booker memorial symposium. Rotterdam, pp 1-9

23. Harden C, Hutchinson T, Eeri M, Moore M (2006) Investigation into the effects of foundation uplift on simplified seismic design procedures. Earthq Spect 22(3):663-692. https://doi.org/ 10.1193/1.2217757

24. Hu X, Zhang Y, Guo L, Wang J, Cai Y, Fu H, Cai Y (2018) Cyclic behavior of saturated soft clay under stress path with bidirectional shear stresses. Soil Dyn Earthq Eng 104:319-328. https://doi.org/10.1016/j.soildyn.2017.10.016

25. Hyde FL, Ward SJ (1985) A pore pressure and stability model for a silty clay under repeated loading. Geotechnique 35(2):113-125

26. Hyodo M, Yamamoto Y, Sugiyama M (1994) Undrained cyclic shear behaviour of normally consolidated clay subjected to initial static shear stress. Soils Found 34(4):1-11

27. Ishihara K (1996) Soil behaviour in earthquake geotechnics

28. Itasca F (2000) Fast Lagrangian analysis of continua. Itascas Consulting Group Inc., Minneapolis

29. Izadi A, Soumehsaraei Nazemi Sabet M, Jamshidi Chenari R, Ghorbani A (2019) Pseudo-static bearing capacity of shallow foundations on heterogeneous marine deposits using limit equilibrium method. Mar Georesour Geotechnol 37(10):1163-1174. https://doi.org/10.1080/1064119X.2018.1539535

30. Jadar CM, Ghosh S (2016) Seismic bearing capacity of shallow strip footing using horizontal slice method. Int J Geotech Eng 11(1):38-50. https://doi.org/10.1080/19386362.2016.1183074

31. Karakan E, Sezer A, Tanrinian N (2019) Evaluation of effect of limited pore water pressure development on cyclic behavior of a nonplastic silt. Soils Found 59(5):1302-1312. https://doi. org/10.1016/j.sandf.2019.05.009

32. Kumar J, Rao M (2002) Seismic bearing capacity factors for spread foundations. Géotechnique 52(2):79-88

33. Lee KL, Albaisa A (1974) Earthquake induced settlements in saturated sands. J Geotech Eng Div 100(4):387-406

34. Loukidis D, Salgado R (2009) Bearing capacity of strip and circular footings in sand using finite elements. Comput Geotech 36:871-879

35. Martin GR, Finn WD, Seed HB (1975) Fundamentals of liquefaction under cyclic loading. J Geotech Eng Geotech Div 101:423-438

36. Martin JR, Olgun CG, Mitchell JK, Durgunoglu HT (2004) Highmodulus columns for liquefaction mitigation. J Geotech Geoenviron Eng 130(June):561-571

37. Martínez E, Patiño H, Galindo R (2017) Evaluation of the risk of sudden failure of a cohesive soil subjected to cyclic loading. Soil Dyn Earthq Eng 92:419-432

38. Matasovíc N, Vucetic M (1995) Generalized cyclic-degradationpore-pressure generation model for clays. J Geotech Eng 121(7376):33-42

39. Meyerhof GG (1951) The ultimate bearing capacity of foundations. Geotechnique 2(4):301-332

40. Meyerhof GG (1953) The bearing capacity of foundations under eccentric and inclined loads. In: Proceedings of the 3rd international conference on soil mechanics and foundation engineering, vol 1, pp 440-445

41. Nazem M, Carter JP, Airey DW (2010) Arbitrary LagrangianEulerian method for non-linear problems of geomechanics. https://doi.org/10.1088/1757-899X/10/1/012074
42. Ohara S, Matsuda H (1988) Study on the settlement of saturated clay layer induced by cyclic shear. Soils Found 28(3): 103-113

43. Pane V, Vecchietti A, Cecconi M (2016) A numerical study on the seismic bearing capacity of shallow foundations. Bull Earthq Eng 14:2931-2958

44. Panique Lazcano DR, Galindo Aires R, Marañón Olalla C (2021) Methodology for calculate bearing capacity of soft soils under cyclic loading. IOP Conf Ser Earth Environ Sci 684(1):012023. https://doi.org/10.1088/1755-1315/684/1/012023

45. Panique Lazcano DR, Galindo Aires R, Patiño Nieto H (2020) Bearing capacity of shallow foundation under cyclic load on cohesive soil. Comput Geotech 123:103556. https://doi.org/10. 1016/j.compgeo.2020.103556

46. Patiño Nieto CH (2009) Influencia de la combinación de tensiones tangenciales estáticas y cíclicas en la evaluación de parámetros dinámicos de un suelo cohesivo. $\mathrm{PhD}$ thesis, Universidad Politécnica de Madrid

47. Patiño H, Soriano A, González J (2013) Failure of a soft cohesive soil subjected to combined static and cyclic loading. Soils Found 53(6):910-922

48. Polito CP, Green RA, Lee J (2008) Pore pressure generation models for sands and silty soils subjected to cyclic loading. J Geotech Geoenviron Eng 10(134):1490-1500

49. Ren XW, Xu Q, Xu CB, Teng JD, Lv Sh (2018) Undrained pore pressure behavior of soft marine clay under long-term low cyclic loads. Ocean Eng 150:60-68. https://doi.org/10.1016/j.oceaneng. 2017.12.045

50. Sağlam S, Bakir S (2017) Models for pore pressure response of low plastic fines subjected to repeated loads. J Earthq Eng 22(6):1027-1041. https://doi.org/10.1080/13632469.2016. 1269697

51. Sarma SK, Iossifelis IS (1990) Seismic bearing capacity factors of shallow strip footings. Geotechnique 40(2):265-273

52. Seed HB, Idriss IM (1971) A simplified procedure for evaluating soil liquefaction potential. $J$ Soil Mech Found Div 97(9):1249-1273

53. Seed HB, Martin PP, Lysmer J (1975) The generation and dissipation of pore water pressures during soil liquefaction. University of California, Berkeley, Technical report

54. Shi Z, Buscarnera G, Finno RJ (2018) Simulation of cyclic strength degradation of natural clays via bounding surface model with hybrid flow rule. Numer Anal Methods Geomech, pp 1-22

55. Shinohara T, Tateishi T, Kubo K (1960) Bearing capacity of sandy soil for eccerntric and inclined load and lateral resistance of single piles embedded in sandy soil. In: Proceedings 2nd world conference on earthquake engineering, pp 265-280. Tokyo

56. Sitharam TG, Govindaraju L (2007) Pore pressure generation in silty sands during cyclic loading. Geomech Geoeng 2(4):295-306. https://doi.org/10.1080/17486020701670460

57. Tsai CC, Mejia LH, Meymand P (2014) A strain-based procedure to estimate strength softening in saturated clays during earthquakes. Soil Dyn Earthq Eng 66:191-198

58. Yasuhara K (1994) Postcyclic undrained strength for cohesive soils. J Geotech Eng 120(11):1961-1979

Publisher's Note Springer Nature remains neutral with regard to jurisdictional claims in published maps and institutional affiliations. 